Research Article

\title{
Seismic Performance Analysis of a Connected Multitower Structure with FPS and Viscous Damper
}

\author{
Xiaohan Wu $(D$, Jun Wang, and Jiangyong Zhou \\ Research Institute of Structure Engineering and Disaster Reduction, College of Civil Engineering, Tongji University, \\ Shanghai 200092, China
}

Correspondence should be addressed to Xiaohan Wu; xhwu@tongji.edu.cn

Received 21 April 2018; Revised 31 July 2018; Accepted 12 August 2018; Published 8 October 2018

Academic Editor: Gloria Terenzi

Copyright (C) 2018 Xiaohan Wu et al. This is an open access article distributed under the Creative Commons Attribution License, which permits unrestricted use, distribution, and reproduction in any medium, provided the original work is properly cited.

A high four-tower structure is interconnected with a long sky corridor bridge on the top floor. To reduce the earthquake responses and member forces of the towers and sky corridor bridge, a passive control strategy with a friction pendulum tuned mass damper (FPTMD) was adopted. The sky corridor bridge was as the mass of FPTMD. The connection between the towers and the sky corridor bridge was designed as flexible links, where friction pendulum bearings (FPBs) and viscous dampers were installed. Elastoplastic time-history analysis was conducted by using Perform-3D model to look into its seismic behavior under intensive seismic excitation. The optimal design of the FPTMD with varying friction coefficients and radius of friction pendulum bearing (FPB) under seismic excitations was carried out, and the seismic behavior of the structure was also investigated at the same time. Results show that, for this four-tower connected structure, the friction pendulum tuned mass damper (FPTMD) has very well effect on seismic reduction. The structure can meet the seismic resistance design requirements.

\section{Introduction}

Nowadays, when building a high-rise building, height is not the only pursuit. More unique forms are used to show the rich connotation and vitality of buildings. Connected structures conform to these requirements, and many connected structures in varied forms have been or are being built in recent years. Most of them are urban landmark buildings and the symbol of economic and social development. In the early days, most connected tower structures were symmetrical. Recently, however, more and more asymmetric connection towers have emerged. The types of the connection between corridor and building can be classified as rigid connection and flexible or weak connection. With rigid connection, corridors are totally constrained by towers. In order to coordinate the displacement between different towers, corridors are, normally, connected to core tube or shear wall of the primary structure. Rigid connection was used in most of the connected structures, such as La Defense Arch (110 m high), Pairs; Bocom Financial Towers (235 m high), Shanghai; CCTV main building (234 m high),
Beijing; and Marina Bay Sands, Singapore (198 m high). When the flexible connection is adopted, the corridors are allowed to move relative to the primary structure. Furthermore, some damping devices may be set between the corridors and the primary towers to reduce vibration, such as Petronas Twin Towers (452 m high), Kuala Lumpur, and Museum of Modern Art, Beijing. The irregularity and complexity of structures are inevitable for these special buildings. It is very important to set reasonable seismic performance goals and carry out structural analysis in detail. $\mathrm{Lu}$ et al. [1] carried out shaking table model test on a complex high-rise building with two towers of different heights connected by trusses. Zhou et al. [2] performed shake table model test for a high-rise, multitower connected hybrid structure. Besides experimental investigation, with the development of software and personal computer, using nonlinear analysis method to evaluate structural seismic performance is becoming a trend. Wu et al. [3] conducted a seismic evaluation of an asymmetrical twin-tower rigidconnected structure (278 $\mathrm{m}$ high). Zhou et al. [4] evaluated a multitower connected building by using three software 
programs and verified the digital results by comparing with those of shake table model test.

In order to reduce the seismic response or the interaction in different parts of the connected structure, seismic energy dissipation technology was applied in this type of structure gradually. Bhaskararao and Jangid [5] carried out seismic analysis of structures connected with friction dampers. The analysis results show that if the friction of the damper is properly chosen, the earthquake response of the buildings with different natural frequencies, which were connected by friction dampers, could be reduced effectively. Hwasung et al. [6] studied seismic response of dynamically similar adjacent structures connected with viscous dampers. Chen and Han [7] carried out a series of research on a long-span connected tall building structure with viscous dampers, which included inelastic dynamic time-history analysis under rare earthquake, shaking table test, and the control effects of vicious dampers.

While it has a long history for TMD used in wind vibration control for high-rise building, TMD has also been applied to structural earthquake resistance. Huber [8] practiced large TMD system in two high-rise buildings and showed good damping effect on seismic reduction. By linear and nonlinear time-history analysis, Garrido and Sarrazin [9] theoretically studied earthquake responses of structures with different damper parameters, and the effectiveness of seismic reduction of the TMD was evaluated. Chung et al. [10] investigated the optimal design of a friction pendulum tuned mass damper (FPTMD) with varying friction coefficients for wind-excited high-rise structures.

Friction pendulum bearings are sliding devices that utilize a spherical surface to provide a restoring force and friction to dissipate energy. It has been used for base isolation of buildings and seismic protection of bridges. Mosqueda et al. [11] conducted experiments on a rigid-block frame supported by four bearings on the earthquake simulator platform to evaluate friction pendulum bearings under multiple components of excitation. Becker et al. [12] practiced a dynamic unidirectional shake table test of a steel frame isolated with triple friction pendulum bearings, in which the ground motion input was increased until failure occurred in the isolation level.

When the tuned mass damper (TMD) frequency is tuned to the fundamental frequency near the primary structure, the energy of the structure vibration will be transferred to TMD. The damper of the TMD can also dissipate the transferred energy from the structure excited by earthquake. In this paper, in order to reduce the earthquake responses of a high four-tower structure connected with a long sky corridor bridge on the top floor, a passive control strategy with a friction pendulum tuned mass damper (FPTMD) was adopted. The mass of sky corridor bridge and the load on it was taken as the mass of TMD. Friction pendulum bearings (FPBs) were used as springs and dampers of TMD. The mass of the sky corridor bridge and the load on it, which belonged to the primary structure originally, were turned to be the mass of the TMD. With the control strategy, not only the mass was reduced from the primary structure but also the additional mass for TMD could be omitted. Consequently, structural safety under earthquake can be improved. The finite element analysis models of this building were developed by using NosaCAD, which was used to form nonlinear finite element analysis models for Perform-3D. The two pieces of nonlinear structural analysis software have been widely used in structural analysis [13-16]. The optimal design of the FPTMD with varying friction coefficients and radius of friction pendulum under seismic excitations was carried out by elastoplastic time-history analysis in Perform3D. Finally, the effect of seismic reduction was presented and discussed by comparing the nonlinear dynamic responses such as displacement, interstory drift, and damage between the structure with and without controlling devices.

\section{Description of the Structure}

Chongqing Raffles City (Figure 1) is located near Chaotianmen Square, facing the junction of the Yangtze River and the Jialing River, with a total gross floor area about $1,123,000 \mathrm{~m}^{2}$. It is composed of 8 high-rise buildings, 6 -story commercial podium, and 3-story basement. And it is an urban complex integration of shopping mall, high-end residence, office building, service apartment, and hotel. The 8-tower building has an appearance similar to Chinese ancient fleet. The height of T1, T2, T3S, T4S, T5, and T6 is basically the same. They are collectively called the South Tower. The T3N and T4N are collectively called the "North Tower." The layout of the towers is shown in Figure 2.

In South Towers, the connected building (Figure 3) which consists of T2, T3S, T4S, and T5 tower was studied in this paper. T2, T3S, T4S, or T5 tower each has a total height of about 238 meters. T2 and T5 towers, which have a typical story height of 3.5 meters and 47 stories, are used for highend residence. T3S and T4S towers are office buildings (half of the T4S tower is apartment with a story height of 3.5 meters), which have a typical story height of 4.3 meters. There are 40 stories in T3S tower while 43 stories in T4S tower. T2, T3S, T4S, and T5 towers are connected to each other on the rooftop by a sky corridor bridge which is about $300 \mathrm{~m}$ long, $30 \mathrm{~m}$ wide, and about $250 \mathrm{~m}$ above the ground (Figure 4). The FPBs are set on the top of towers to support the sky corridor bridge (Figure 5). Besides, there are several damping devices connecting the towers and the sky corridor bridge.

According to the Chinese Code for Seismic Design of Building (CSDB, GB50011-2010) [17] and Technical Specification for Concrete Structures of Tall Building (TSCSTB, JGJ3-2010) [18], the main characteristics of this structure, which are beyond the limitation of the Chinese code, can be summarized as follows:

(1) The height of these towers is beyond the specified maximum height of $220 \mathrm{~m}$ for SRC frame and RC core tube system. And the height-width ratio of these towers both exceeds the limitation ruled in the TSCSTB of 7.

(2) The ratios of the maximum horizontal displacement to the average horizontal displacement in T2, T4S, and $\mathrm{T} 5$ towers are 1.38 , and the ratio in $\mathrm{T} 3 \mathrm{~S}$ tower is 


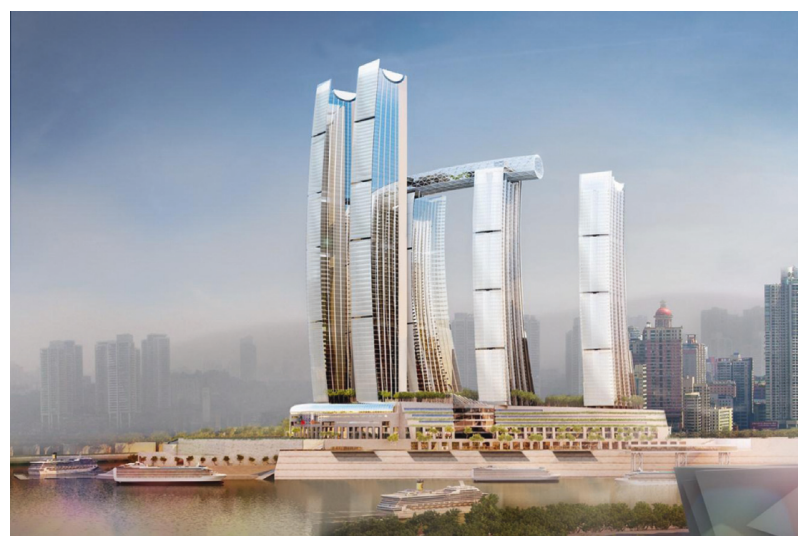

FIGURe 1: Perspective view of the buildings.

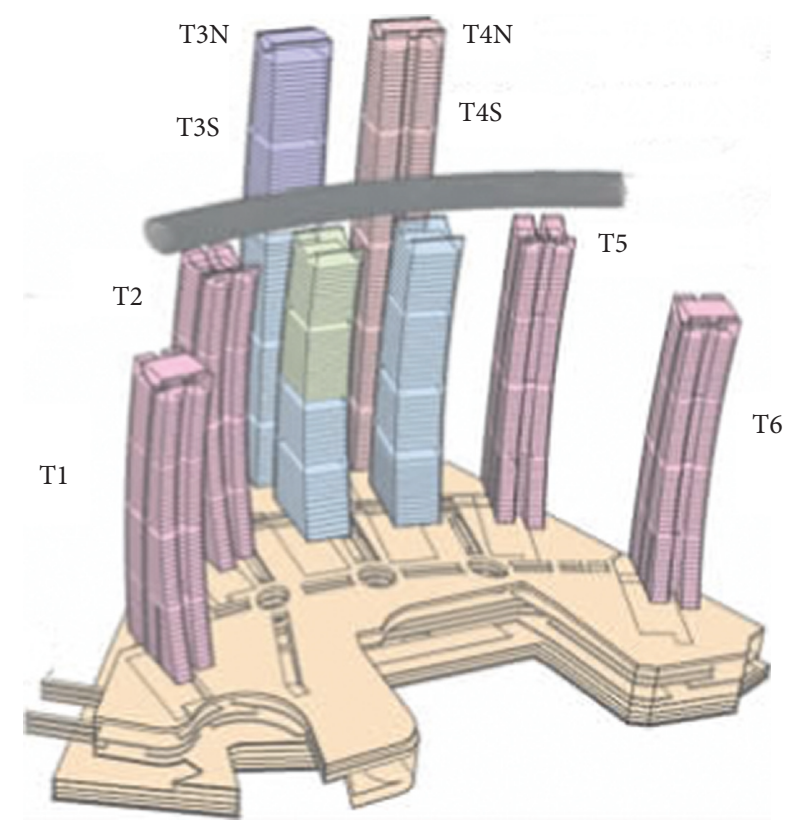

FIgURE 2: The layout of the towers.

1.30. According to the TSCSTB, if the ratio exceeds 1.2, the structure belongs to torsion irregular structure.

(3) A few floors of the towers draw back more than 4 meters, so the towers belong to vertical irregular structure according to the TSCSTB.

\section{Analysis Model}

3.1. Parameters of Materials. In elastoplastic analysis, characteristic values were adopted for the strength of materials. Concrete C30 was adopted for plates and beams, and C60 was adopted for the core tube wall and the frame tube column. The normal rebar was employed with HPB235, HPB335, and HRB400, and profile steel was employed with Q345B.

3.2. Finite Element Model for Structure Components. The bilinear and trilinear moment-curvature hysteretic models were adopted for the elastoplastic segments of steel beams, concrete beams, and steel-reinforced concrete beams, respectively, and the fiber model was employed to describe the nonlinear behavior for the frame columns and braces. The frame member consisted of three components, one in middle was linear elastic and the others at two ends were elastoplastic.

Macrolayered element was adopted to simulate the shear wall component. One-dimensional fiber element is used for simulating the compression-bending effect, while using nonlinear or linear shear model for the shear effect in plane and elastic model for the bending, shear, and torsion effect out of plane.

The intent of the Perform-3D action-deformation relationship, with points $\mathrm{Y}, \mathrm{U}, \mathrm{L}$, and $\mathrm{R}$, is to catch the main characters of the material behavior, namely, the initial stiffness, strain hardening, ultimate strength, and strength loss [19] (Figure 6). The main intent of the Perform-3D hysteresis loop is to represent the dissipated energy (the area of the loop). This area is influenced by stiffness degradation under cyclic loading. By the different parameters set, the certain action-deformation relationship and hysteresis loop outline the actual inelastic behavior of related materials.

Steel constitutive model with bulking or nonbulking is available in Perform-3D. Nonbulking steel model was applied for reinforcement. Concrete constitutive model with Mander stress-strain relationship should be transferred in the action-deformation relationship of Perform-3D, which can be determined by 5 parameters, and strength loss was taken into account. The moment-curvature hysteretic relationship for the frame element section was also defined by the action-deformation relationship of Perform-3D, which can be determined by 3 parameters or 5 parameters.

As known that energy can be dissipated by the nonlinear component under cyclic loading, and the amount of the dissipated energy can be represented by the area of hysteretic loop. In Perform-3D, parameters of energy degradation are determined by the maximum deformation and can be specified optionally (Figure 7). Perform-3D gives the required energy degradation through adjusting the unloadingload stiffness, and the coefficient of energy degradation is taken as the ratio of the area of degraded and nondegraded hysteretic loop, which can be obtained from experiment and numerical simulation. In this paper, the degradation coefficients of concrete were defined as shown in Figure 8.

The friction-pendulum isolator element is shown in Figure 9. This element connects to two nodes and consists of a sliding surface connected to the nodes by rigid links. The shear behavior is as shown in Figure 10. Before it slips, the isolator has initial stiffness $K_{0}$. The slip force depends on the bearing force in compression and the friction coefficient. An approximation for the plasticity model parameter $K_{0}$ in terms of the yield (slip) displacement $D_{0}$ is given by Mosqueda et al. [11]:

$$
K_{0}=\frac{\mu_{0} W}{D_{0}}
$$

where $W$ is the bearing force, $\mu_{0}$ is the static friction coefficient and 0.02 larger than the kinetic friction coefficient, and the yield (slip) displacement $D_{0}$ is set as $0.25 \mathrm{~mm}$ [11]. 


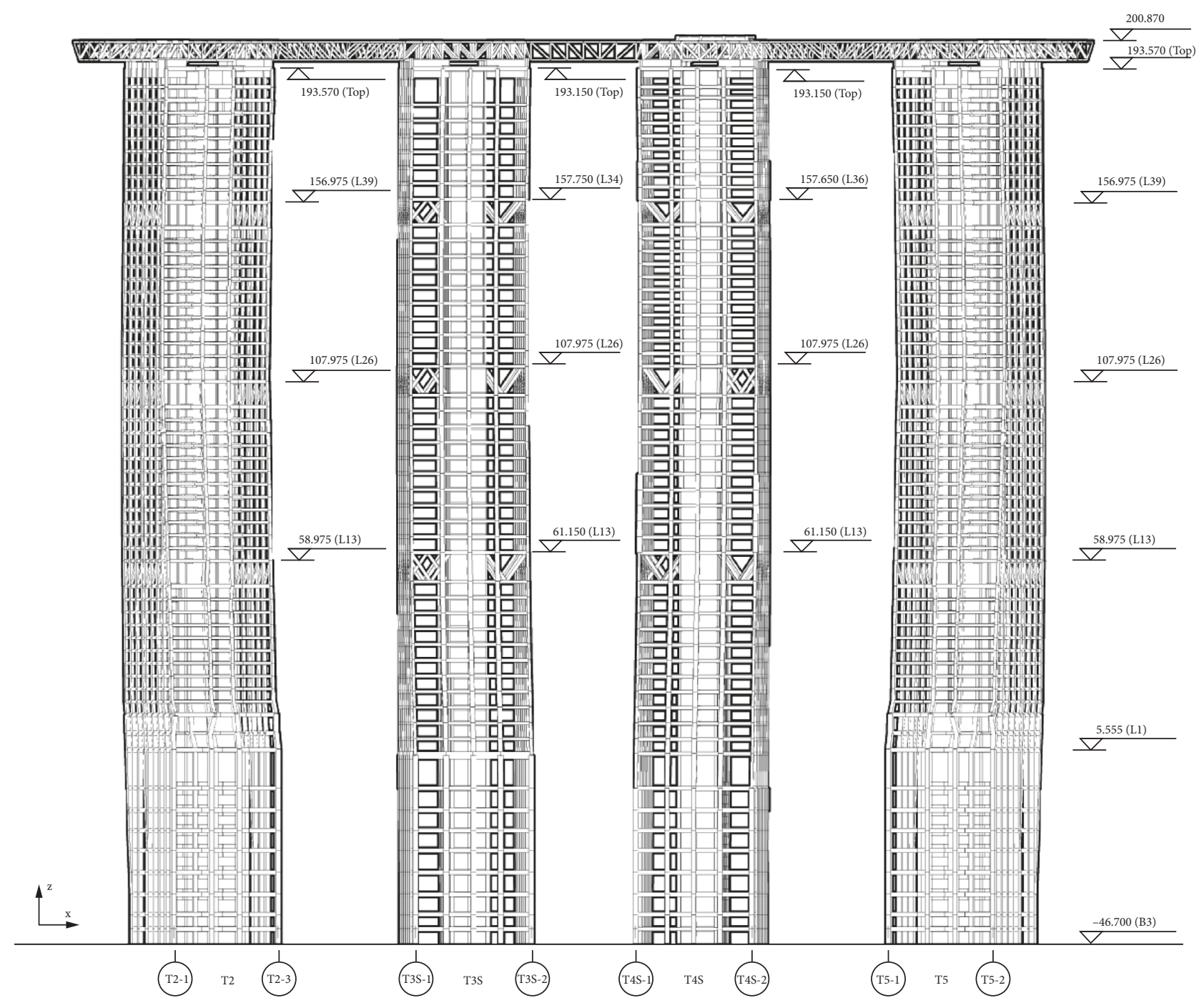

FIGURE 3: Structure elevation.

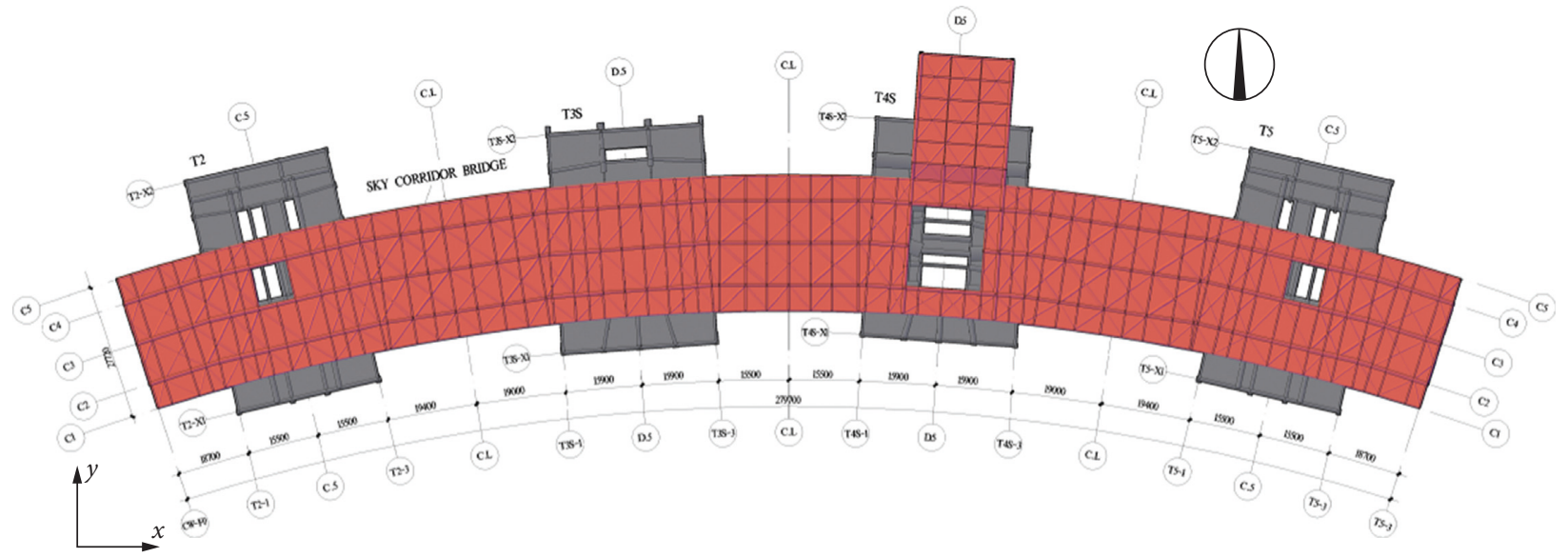

FIgURE 4: Structural plan layout of the towers and the sky corridor bridge. 


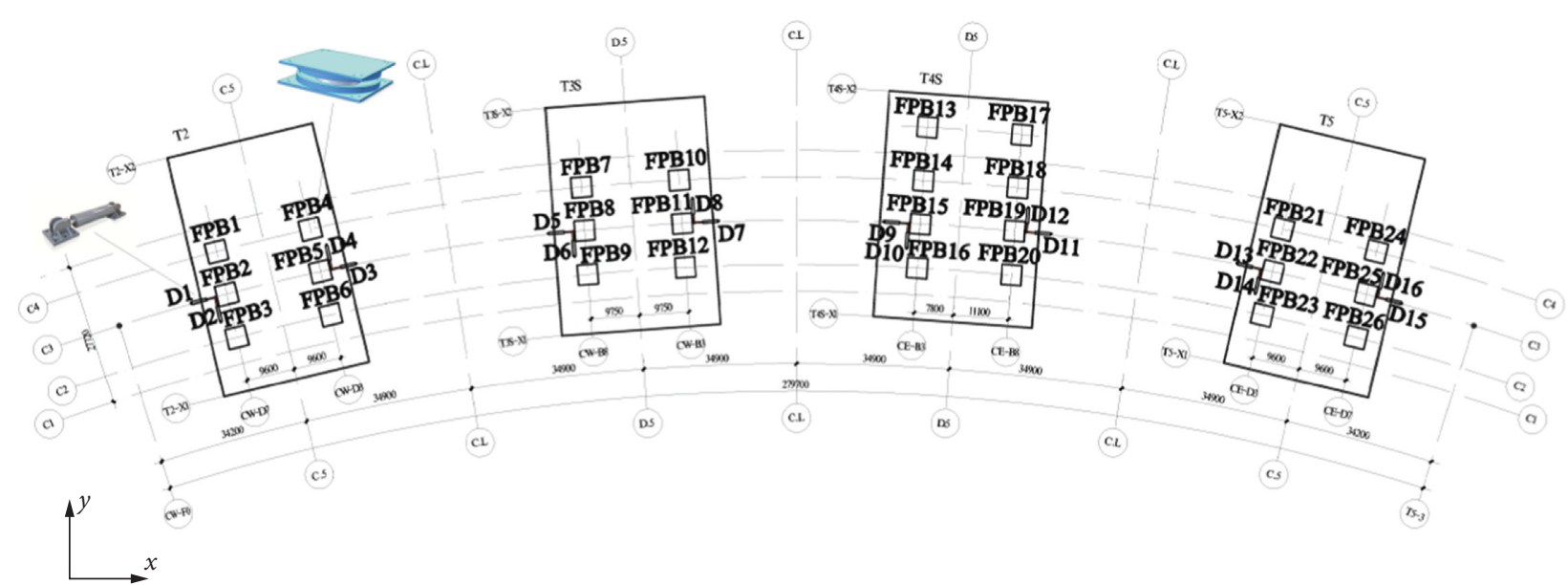

FPBxx (friction pendulum bearing)

DX (viscous damper)

Figure 5: Plan layout of the FPB and viscous damper on the top of towers.

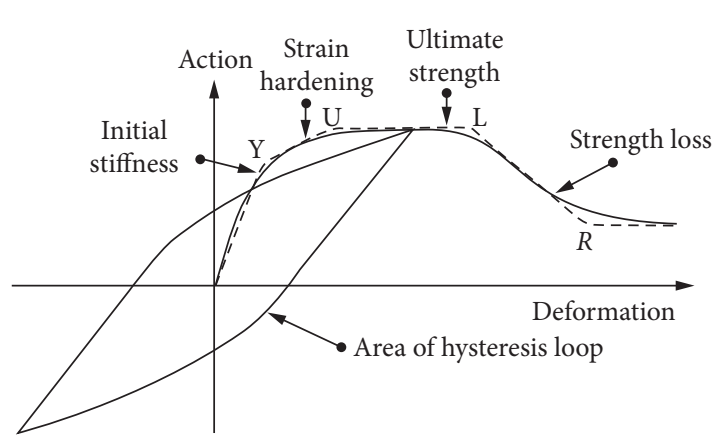

Figure 6: Main aspects of inelastic behavior in Perform-3D $[19,20]$.

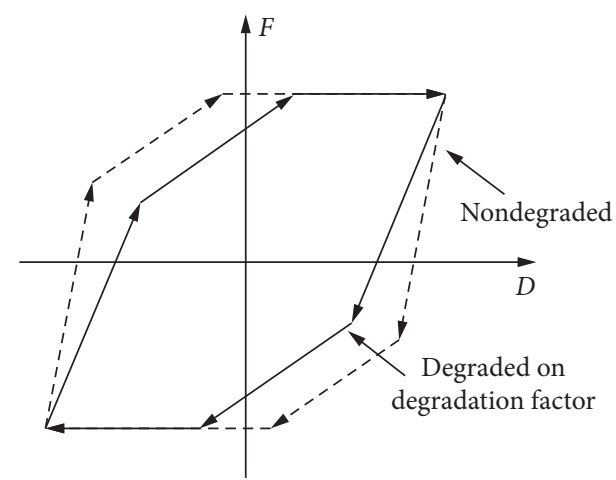

FIgURE 7: Hysteretic loop of energy degradation.

The sliding stiffness or hardening stiffness is equal to the current bearing axial force divided by the radius of the slip surface. The restoring shear force can be

$$
F=\frac{W}{R_{\mathrm{d}}} D+\mu W \operatorname{sgn}(\dot{D})
$$

where $R_{\mathrm{d}}$ is the radius of curvature of the FPB spherical surface, $\mu$ is the kinetic friction coefficient, and $D$ is the slip displacement.

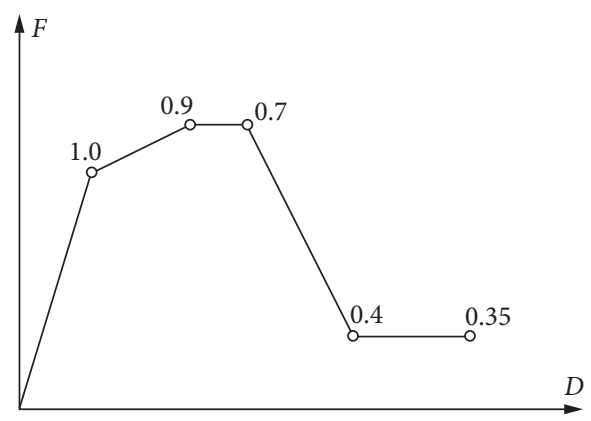

Figure 8: Degradation coefficients of concrete.

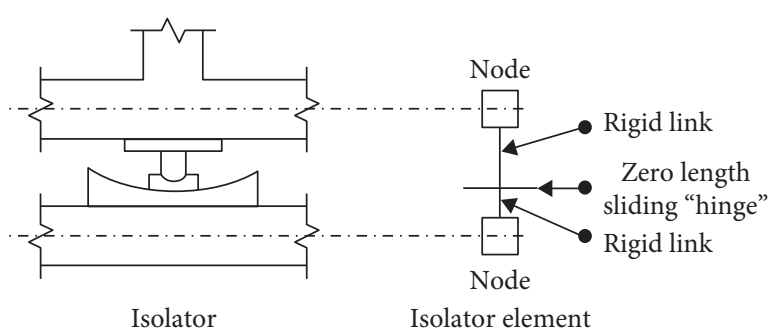

FIGURE 9: Friction pendulum element.

Maxwell model was adopted for viscous bar element. The viscous bar element consists of two components, which are linear elastic bar and fluid damper, respectively. The fluid damper component has no elastic stiffness. Its relationship between axial force and axial deformation rate can be

$$
F=C V^{\alpha},
$$

where $F$ is the axial damper force, $C$ is the damper coefficient, $\alpha$ is the damper exponent, and $V$ is the axial deformation velocity.

3.3. Analysis Model of the Structure. The structural model was established by NosaCAD (Figure 11), and then the model was transformed to Perform-3D by the NosaCAD 


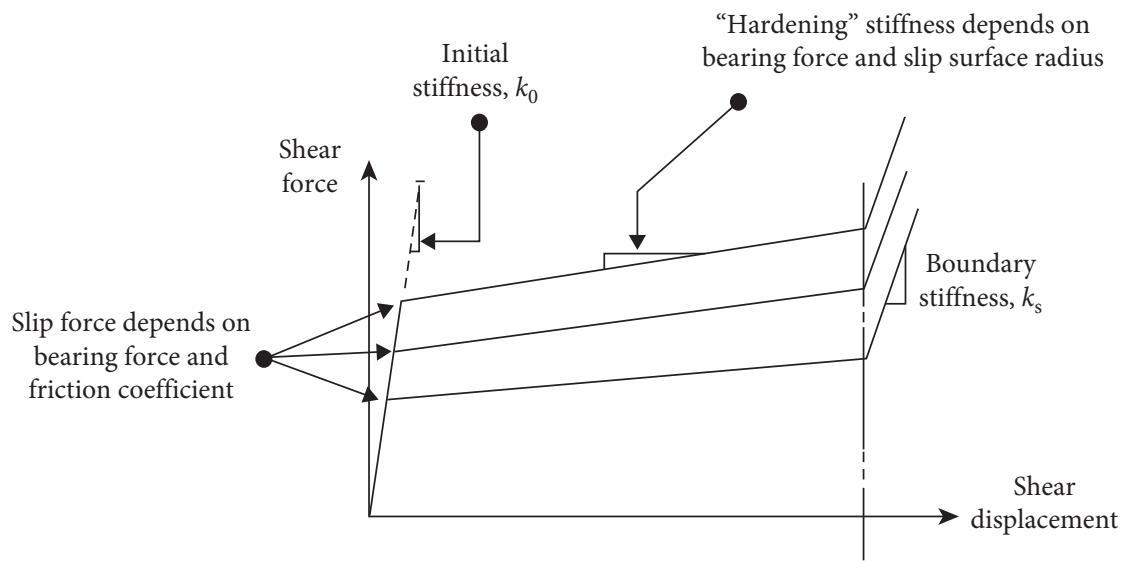

Slip surface boundary

Figure 10: Behavior of friction-pendulum element.

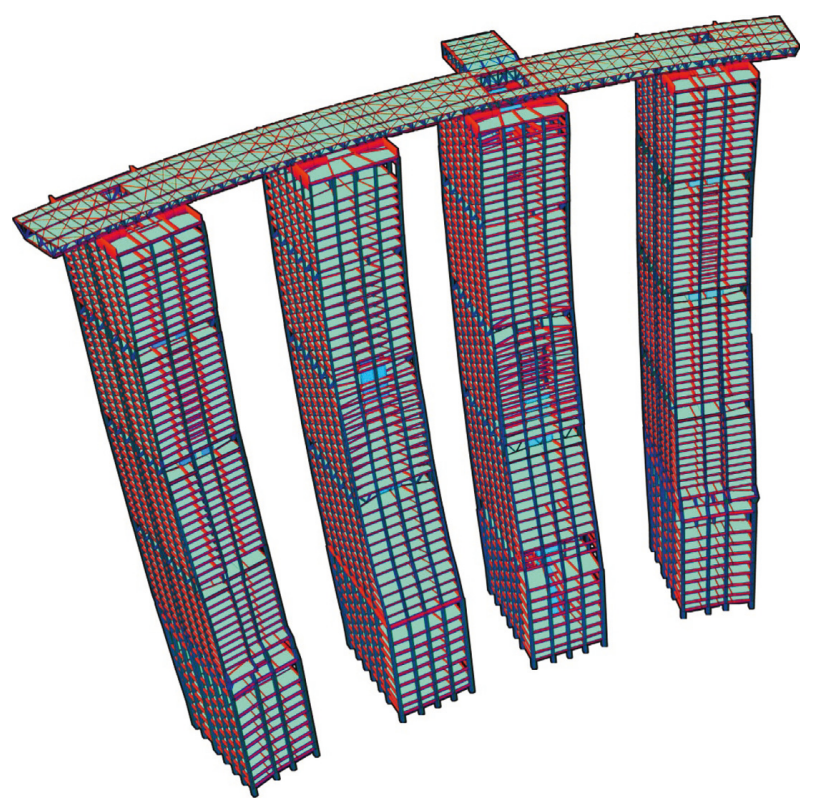

FIgure 11: NosaCAD model.

transforming module [20] (Figure 12). The nonlinear parameters of the hysteretic models such as for momentcurvature, concrete material, steel material, and FPB, which are schematically shown in Figure 6, were also generated by NosaCAD and were shared by Perform-3D [20]. The rigid floor assumption was employed in four towers separately. However, the rigid floor assumption was not adopted for the sky corridor bridge, because it is too long to be suitable for this assumption. The mass of the model is consisted of $100 \%$ dead load, $100 \%$ self-weight, and $50 \%$ live load. The total mass is 796,244 tons in the NosaCAD model and 796,240 tons in the Perform-3D model. The mass of the sky corridor bridge is 37,866 tons in both software models and equals to $4.76 \%$ of the total mass.

\section{Structure Analysis}

In general, when the structure encounters the earthquake, static load such as gravity and service load has already acted

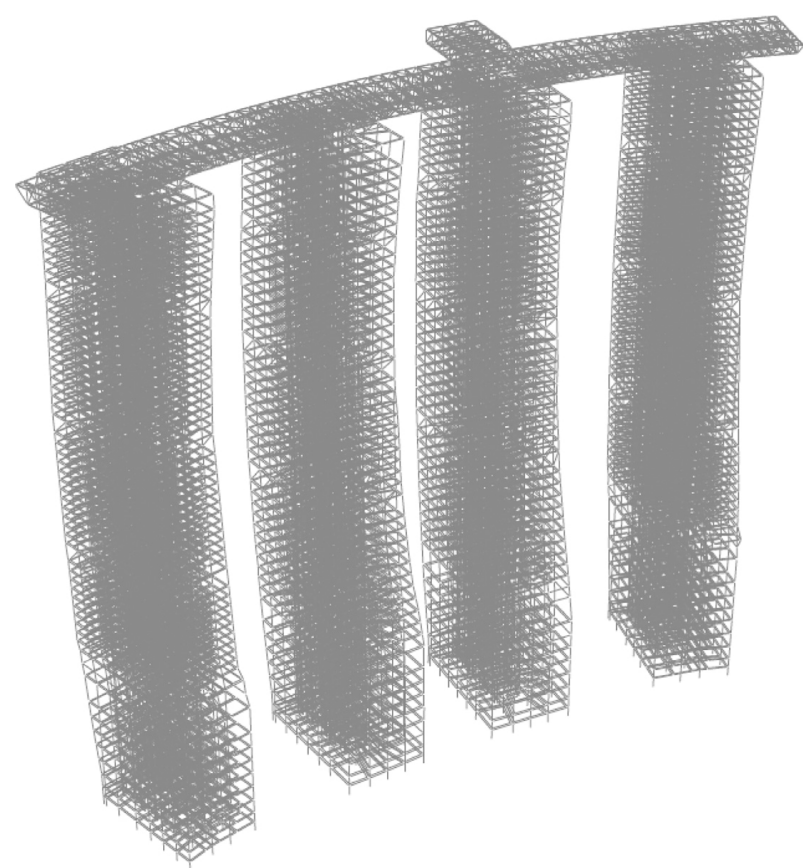

Figure 12: Perform-3D model.

on the structure. Therefore, prior to the nonlinear dynamic time-history analysis, a nonlinear static analysis was performed to obtain the initial stress state in structure members, which served as the initial state of nonlinear dynamic analysis. Meanwhile, a modal analysis was conducted to get the natural vibration characteristics of the structure. Then, the optimal design of the FPTMD with varying friction coefficients and radius of friction pendulum under seismic excitations was carried out. The overall seismic responses and the effect of seismic reduction of the structure were also investigated as well.

4.1. Natural Vibration Characteristic of the Structure. To verify the accuracy of the model transformation from NosaCAD to Perform-3D, an initial judgment was made on 
TABLE 1: Natural vibration characteristic.

\begin{tabular}{lccc}
\hline \multirow{2}{*}{ Number } & \multicolumn{2}{c}{ Period (s) } & Description \\
& NosaCAD & Perform-3D & \\
\hline 1 & 5.791 & 5.740 & Translation in direction $X$ \\
2 & 3.880 & 3.845 & Translation in direction $Y$ \\
3 & 3.596 & 3.555 & Torsion \\
\hline
\end{tabular}

the fundamental dynamic characteristic of the structure. The first three periods and vibration mode shapes obtained from NosaCAD and Perform-3D are listed and shown in Table 1 and Figure 13, respectively. They agree with each other between two models, which mean the parameters of the two models are basically identical.

\subsection{Nonlinear Time-History Analysis}

4.2.1. Input Ground Motions. According to the CSDB, the site soil in this project belongs to type III, which is defined that the overlaying thickness of the site soil is more than $50 \mathrm{~m}$ and the average velocity of shear wave in the soil layer is between $150 \mathrm{~m} / \mathrm{s}$ and $250 \mathrm{~m} / \mathrm{s}$, or the thickness is between $15 \mathrm{~m}$ and $80 \mathrm{~m}$ and the average velocity of shear wave is not more than $150 \mathrm{~m} / \mathrm{s}$. It is specified in the TSCSTB that no less than two earthquake records and a synthetic accelerogram should be selected for elastoplastic time-history analysis. According to the power spectral density properties of type III site soil, three different ground motions were chosen as ground input accelerations to the model: (a) the L0689 series record; (b) the L0223 series record; and (c) the L6501 series record, which is formed artificially according to the CSDB. The parameters of the three records are shown in Table 2. Figure 14 shows the time-history acceleration of L0689 series in three directions and the response spectrums of L0689S wave comparing to the design spectrum in CSDB.

According to the CSDB, buildings in seismic regions should be designed to sustain earthquakes of frequent, moderate, and rare levels, which correspond to $63.2 \%, 10 \%$, and $2 \%$ probability of being exceeded in 50 years, and return period of 50, 475, and about 2475 years, respectively. That is to say, when buildings are designed to be subjected to the influence of frequently occurring earthquakes with an intensity of less than the design intensity, the buildings will not be damaged, or will be only slightly damaged and will continue to be serviceable without repair; when they are subjected to the influence of earthquakes equal to the design intensity, they may be damaged but will still be serviceable after ordinary repair or without repair; when they are subjected to the influence of expected rare earthquakes with an intensity higher than the design intensity, they will neither collapse nor suffer damage that would endanger human lives. According to earthquake safety assessment, the peak ground accelerations (PGA) corresponding to the earthquakes of minor, moderate, and major levels are specified to be $0.027,0.075$, and $0.175 \mathrm{~g}$, respectively.

Since seismic reduction performance under rare earthquake was mainly investigated in this paper, the peak ground acceleration (PGA) of the selected earthquake accelerograms

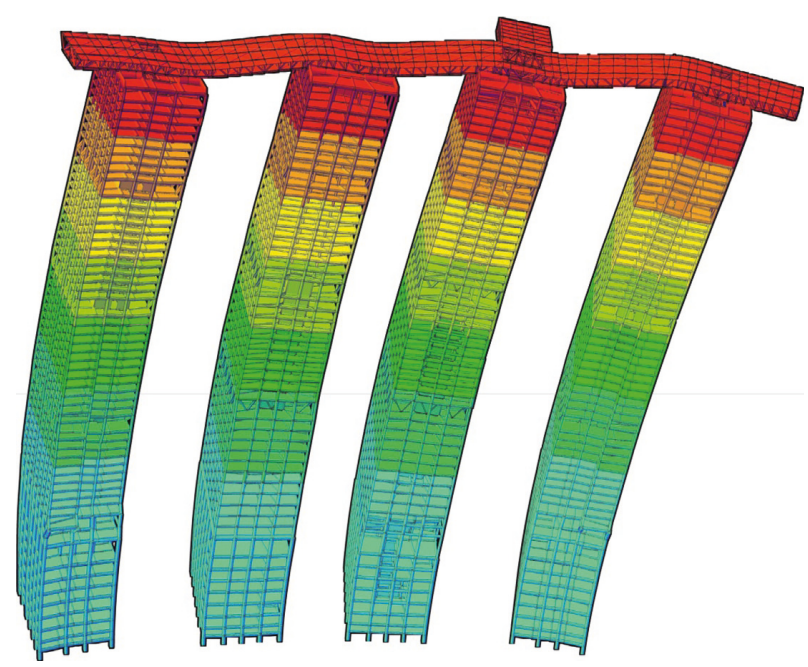

(a)

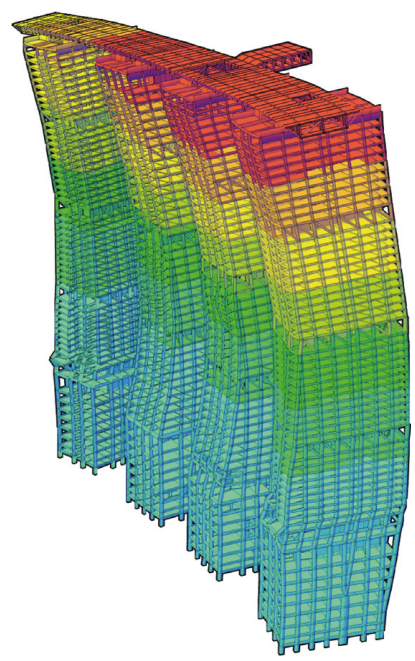

(b)

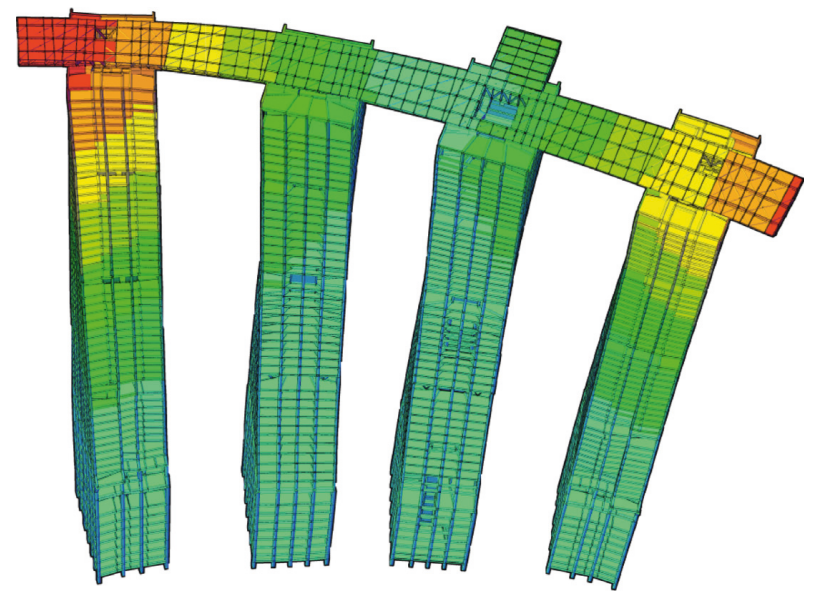

(c)

FIgURE 13: The first three vibration modes: (a) $1^{\text {st }}$ vibration mode, (b) $2^{\text {nd }}$ vibration mode, and (c) $3^{\text {rd }}$ vibration mode.

was scaled to $0.175 \mathrm{~g}$, corresponding to earthquakes of major levels. During the analysis, the three earthquake records were inputted in three principal directions simultaneously (direction 
TABLE 2: Parameters of the earthquake records.

\begin{tabular}{|c|c|c|c|c|}
\hline Label of the record & Component & Label of the direction & Recoding time interval (s) & Recording time (s) \\
\hline L0689S & $\begin{array}{l}\text { L0689 } \\
\text { L0688 } \\
\text { L0690 } \\
\end{array}$ & $\begin{array}{c}\text { Primary } \\
\text { Secondary } \\
\text { Vertical }\end{array}$ & 0.02 & 40 \\
\hline L0223S & $\begin{array}{l}\text { L0223 } \\
\text { L0224 } \\
\text { L0225 } \\
\end{array}$ & $\begin{array}{c}\text { Primary } \\
\text { Secondary } \\
\text { Vertical }\end{array}$ & 0.02 & 40 \\
\hline L6501S & $\begin{array}{l}\text { L6501 } \\
\text { L6502 } \\
\text { L6503 } \\
\end{array}$ & $\begin{array}{c}\text { Primary } \\
\text { Secondary } \\
\text { Vertical }\end{array}$ & 0.02 & 40 \\
\hline
\end{tabular}

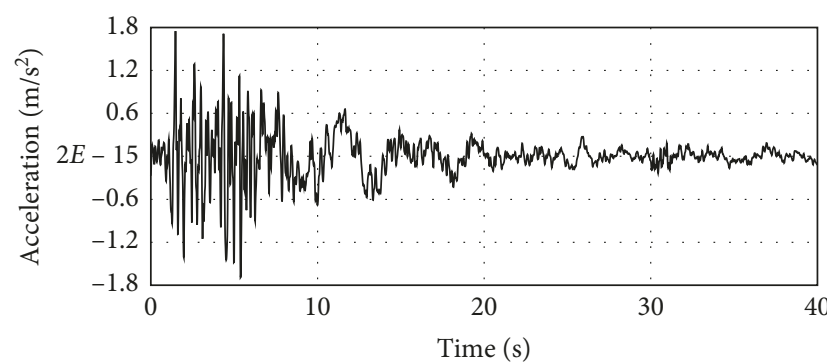

(a)

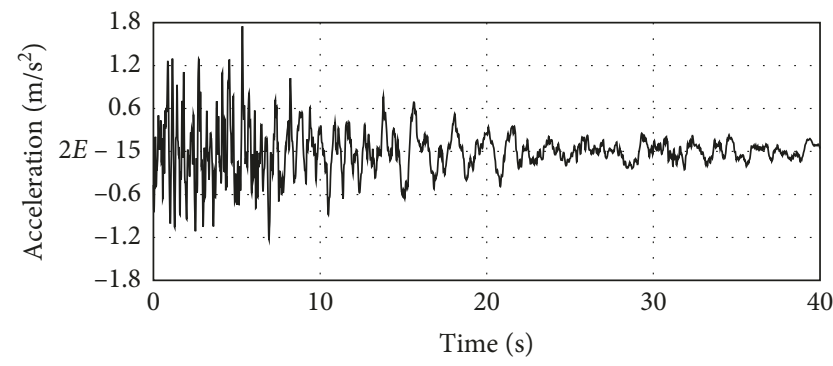

(c)

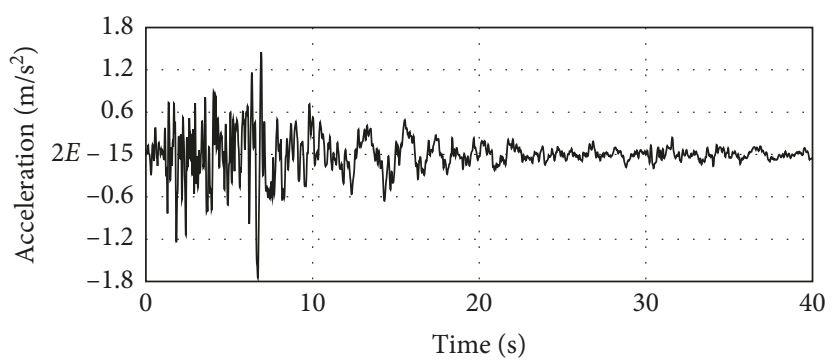

(b)

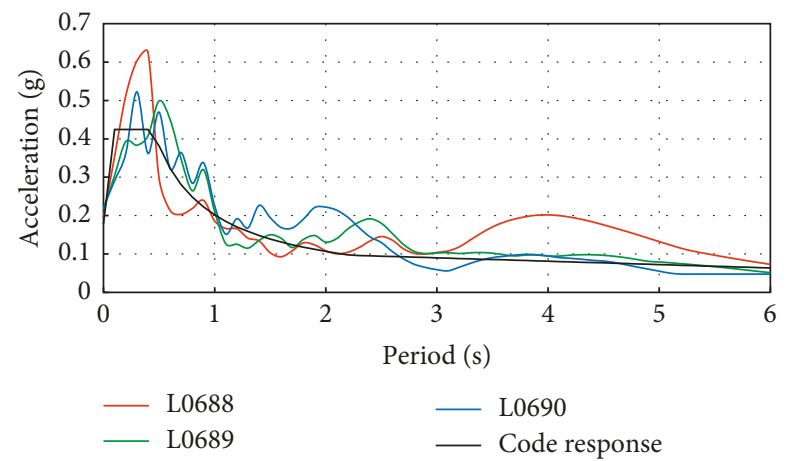

(d)

FIGURE 14: L0689 series accelerogram. Time history of acceleration in (a) secondary direction (L0688), (b) primary direction (L0689), and (c) vertical direction (L0690). (d) Response spectrums compared with the design spectrum in CSDB.

$\mathrm{X}, \mathrm{Y}$, and $\mathrm{Z}$ in Figures 3 and 4) with the PGA ratio of $1: 0.85$ : 0.65 , and $175 \mathrm{~cm} / \mathrm{s}^{2}$ was adopted for the peak accelerograms.

As specified by the TSCSTB, a damping ratio of 0.04 for SRC frame-RC core wall structure system was adopted, and Rayleigh damping was used in integration equation.

4.2.2. Optimization of FPTMD with Varying Coefficients. In order to achieve maximum vibration reduction for the structure, the design parameters of the FPTMD should be optimized. Usually, the minimum structural responses under earthquake are used as the optimization target. In this paper, the displacement responses of the top floor of the 4 towers were taken as the basis for the optimization of the parameters. When the frequency of a tuned mass damper (TMD) is tuned to be close to the fundamental frequency of the primary structure, the dynamic energy will be transferred to the TMD. However, there are more vibration modes participating in seismic response in the high-rise building structure, and the damage in the structure will also cause a change in the structural dynamic characteristics, so it is not suitable to simply set the frequency of FPTMD to the frequency of the first mode of the primary structure. The determination of FPS parameters needs to be searched by a series of calculations. The relationship between the pendulum period of the FPS and the radius of curvature of the spherical surface is as follows:

$$
T_{\mathrm{d}}=2 \pi \sqrt{R_{\mathrm{d}} / g}
$$

where $T_{\mathrm{d}}$ is the pendulum period of the FPS and $R_{\mathrm{d}}$ is the radius of curvature of the FPB spherical surface.

According to formula (4), the relationship between the periods of FPTMD and the radii of curvature of the FPB spherical surface is listed in Table 3 . The FPB with these radii of spherical surface were chosen for searching optimization target.

By the elastoplastic time-history analysis of the structure which has been installed with FPBs with different radii and 
TABLE 3: The relationship between the periods of FPTMD and the radii of curvature of the FPB spherical surface.

\begin{tabular}{lc}
\hline$R_{\mathrm{d}}(\mathrm{mm})$ & $T_{\mathrm{d}}(\mathrm{s})$ \\
\hline 3000 & 3.476 \\
3500 & 3.755 \\
4000 & 4.014 \\
4500 & 4.258 \\
5000 & 4.488 \\
6000 & 4.916 \\
\hline
\end{tabular}

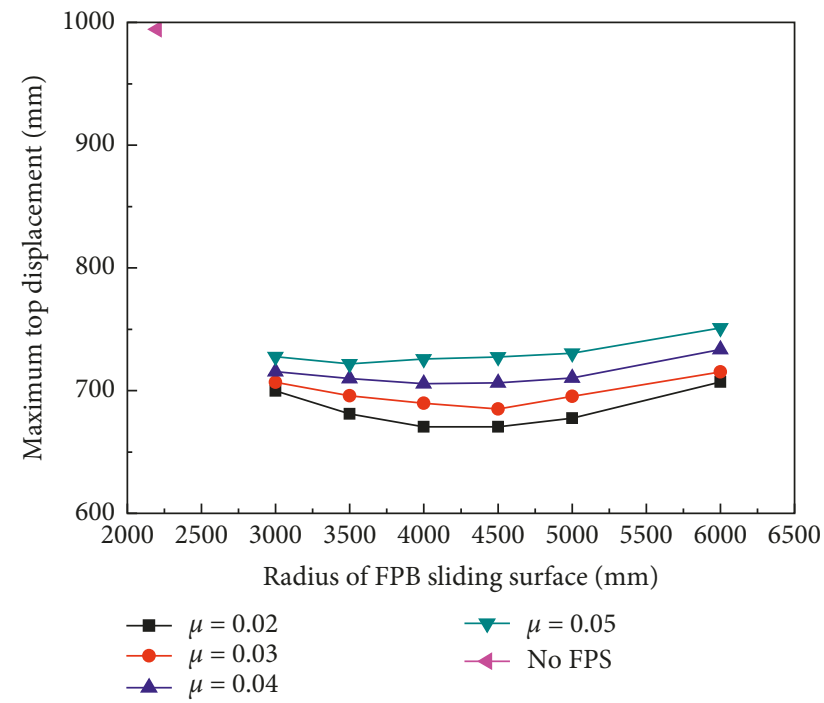

Figure 15: The maximum top displacement of T2 tower with $R_{\mathrm{d}}$ and $\mu$ in the $\mathrm{X}$ direction under L0689S wave.

friction coefficients between tower and sky corridor bridge, the maximum displacement responses of the top of the towers $\mathrm{T} 2$ and $\mathrm{T} 4 \mathrm{~S}$ under different seismic load cases are shown in Figures 15-26. It can be seen from the figures that the maximum top displacements of the structure with FPTMD are obviously smaller than those of the structure without FPTMD. On the whole, in the X direction, the maximum top displacements are relatively smaller when the radius of the curvature of the FPS spherical surface is between $4500 \mathrm{~mm}$ and $5000 \mathrm{~mm}$. Meanwhile, in the $\mathrm{Y}$ direction, the relationship between the radius and the reduction of the maximum top displacements is not very clear. It can also be seen from the figures that the effect of the reduction of the maximum top displacements is better when the friction coefficient of the FPB gets smaller. Considering the effect of the reduction of the maximum top displacements in $\mathrm{X}$ and $\mathrm{Y}$ directions, the radius of curvature of the FPB spherical surface parameters is taken as $4500 \mathrm{~mm}$, and the friction coefficient of the FPB is taken as 0.02 .

Although FPS has its own energy dissipation capacity, in order to prevent its sliding displacement too large to exceed the design limit, viscous dampers are set in FPTMD as shown in Figure 5 to dissipate energy for the FPTMD and limit the sliding displacement of FPBs. Similarly, the design parameters of the viscous damper should also be optimized. When the damper exponent is taken as 0.3 , with varying

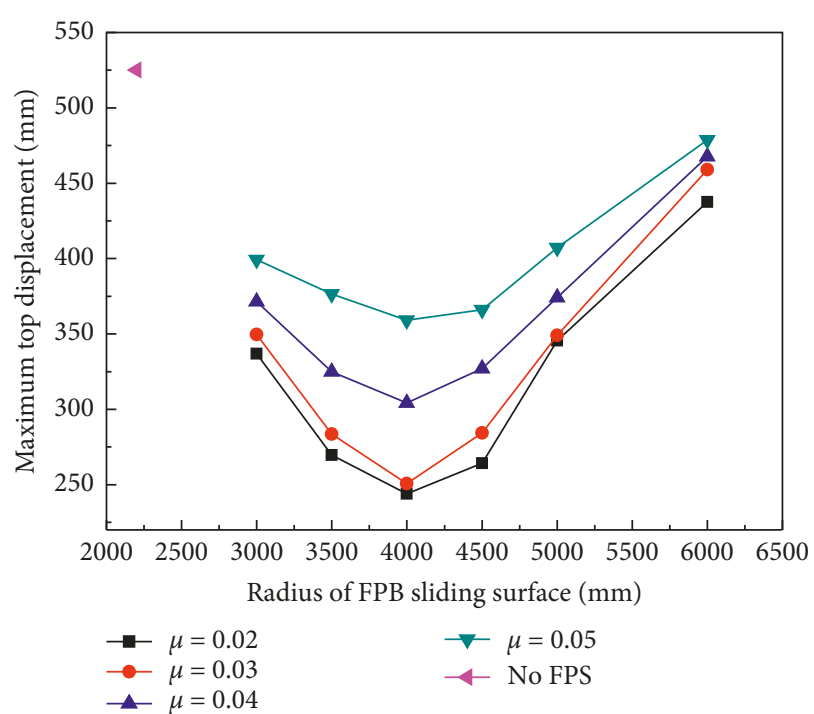

Figure 16: The maximum top displacement of T2 tower with $R_{\mathrm{d}}$ and $\mu$ in the $\mathrm{Y}$ direction under L0689S wave.

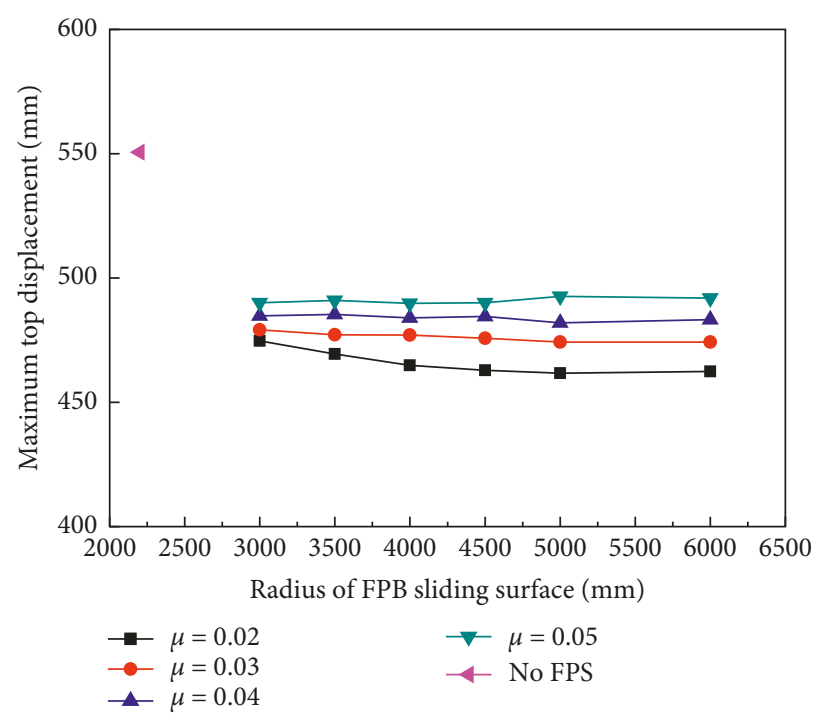

FIgURE 17: The maximum top displacement of T2 tower with $R_{\mathrm{d}}$ and $\mu$ in the $\mathrm{X}$ direction under L0223S wave.

damper coefficients $C$, the maximum displacement responses of the top of the towers T2 and T4S under L0689S wave are shown in Figures 27-30. It can be seen from the figures that in common when the viscous damping coefficients increase, the effect of seismic reduction will be reduced. When the viscous damping coefficient is equal to $50 \mathrm{kN} / \mathrm{mm} / \mathrm{s}$ or $100 \mathrm{kN} / \mathrm{mm} / \mathrm{s}$, the effect of seismic reduction is relatively better.

The trace of the shear force to sliding displacement of FPB No. 15 in the X and Y direction under L0689S wave is shown in Figures 31 and 32, respectively. It can be seen that the sliding displacement of the FPS decreased to a certain degree. The design limit of sliding displacement of FPS is $350 \mathrm{~mm}$. When no viscous damper is set, the maximum sliding displacement of FPBs will reach or even exceed the 


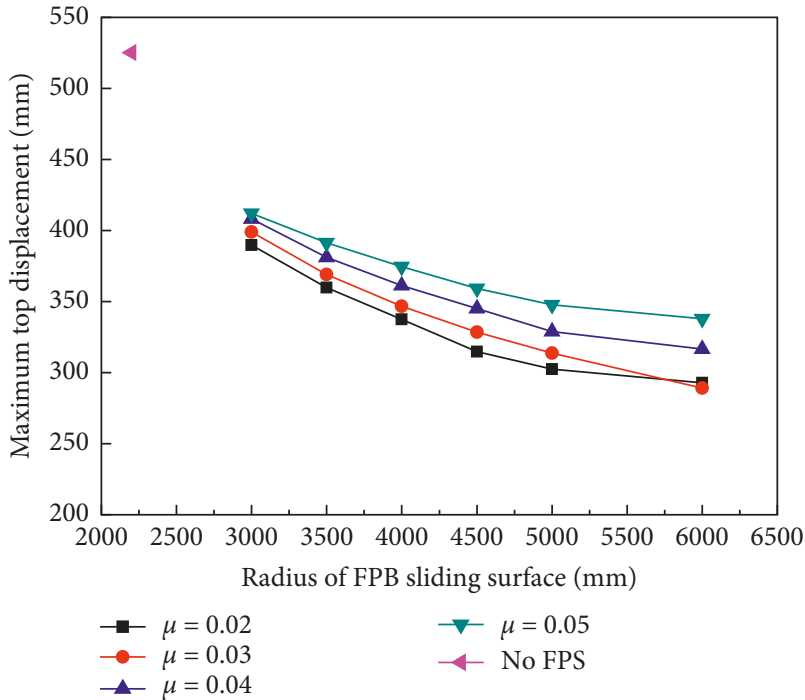

Figure 18: The maximum top displacement of T2 tower with $R_{\mathrm{d}}$ and $\mu$ in the $\mathrm{Y}$ direction under L0223S wave.

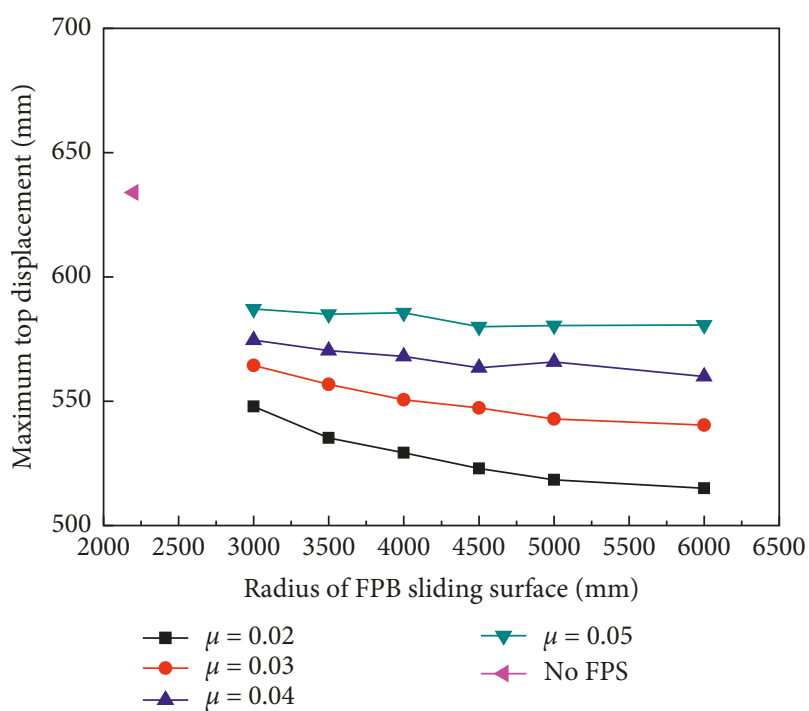

Figure 19: The maximum top displacement of T2 tower with $R_{\mathrm{d}}$ and $\mu$ in the $\mathrm{X}$ direction under L6501S wave.

design limit. After setting the viscous damper, all the maximum sliding displacements of FPBs are within the design limit. The trace of the axial force to axial deformation of dampers D9 and D10 (Figure 5) under L0689S wave is shown in Figures 33 and 34, respectively. The hysteretic curve of the damper is plump, and its energy dissipation capacity is good.

4.2.3. Comparison of Structure Seismic Responses. Since the effect of seismic reduction is close to the best when the radius of the curvature of the FPB spherical surface parameters is taken as $4500 \mathrm{~mm}$ and friction coefficient of the FPB is 0.02 , the damper exponent is equal to 0.3 and the viscous damping coefficient is equal to $100 \mathrm{kN} / \mathrm{mm} / \mathrm{s}$, and the comparison of

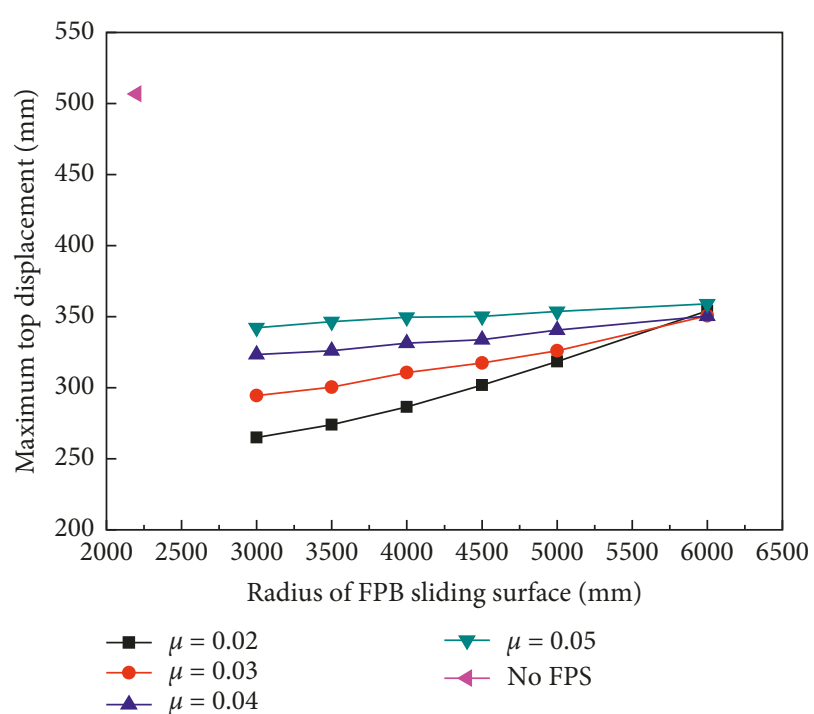

FIgURE 20: The maximum top displacement of T2 tower with $R_{\mathrm{d}}$ and $\mu$ in the $\mathrm{Y}$ direction under L6501S wave.

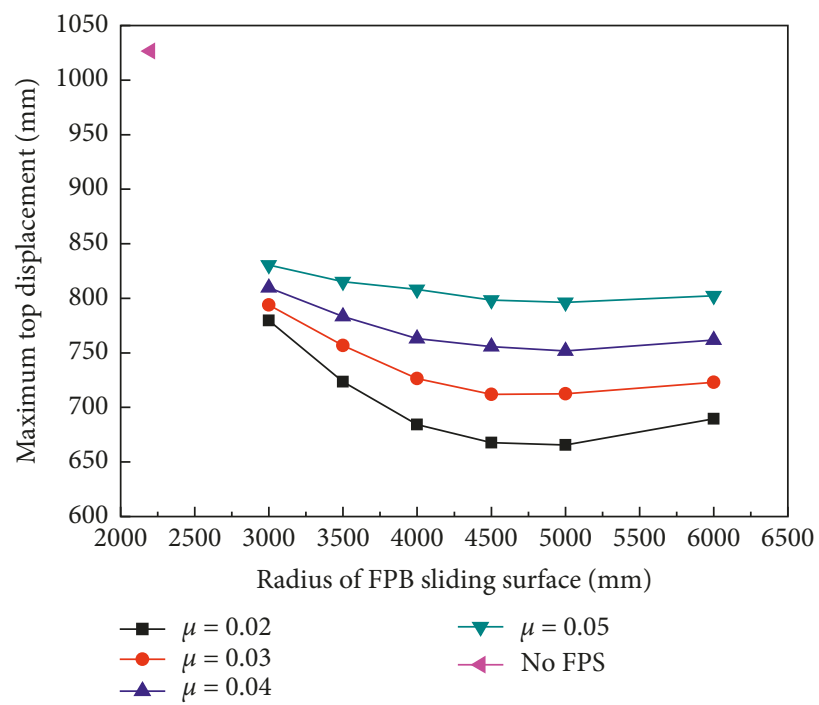

Figure 21: The maximum top displacement of T4S tower with $R_{\mathrm{d}}$ and $\mu$ in the $\mathrm{X}$ direction under L0689S wave.

the structure seismic responses between the model having FPS with aforementioned parameters and the model having no FPS was carried out as follows.

The comparison of the maximum interstory drift of the structure with and without FPS is shown in Table 4. When the FPS and damper are set, the reduction rate of the interstory drift is from $13.27 \%$ to $28.79 \%$ in the $\mathrm{X}$ direction and from $14.29 \%$ to $30.33 \%$ in the $\mathrm{Y}$ direction under different earthquake wave actions. It can be found that the interstory drift responses under L0689S wave are larger than those under L0223S wave and L6501S wave. The interstory drift envelop curves of the towers T2 and T4S under L0689S wave in the $\mathrm{X}$ and $\mathrm{Y}$ direction are shown in Figures 35-38, respectively, and the comparisons of the interstory drift among the tower models with and without FPS and damper 


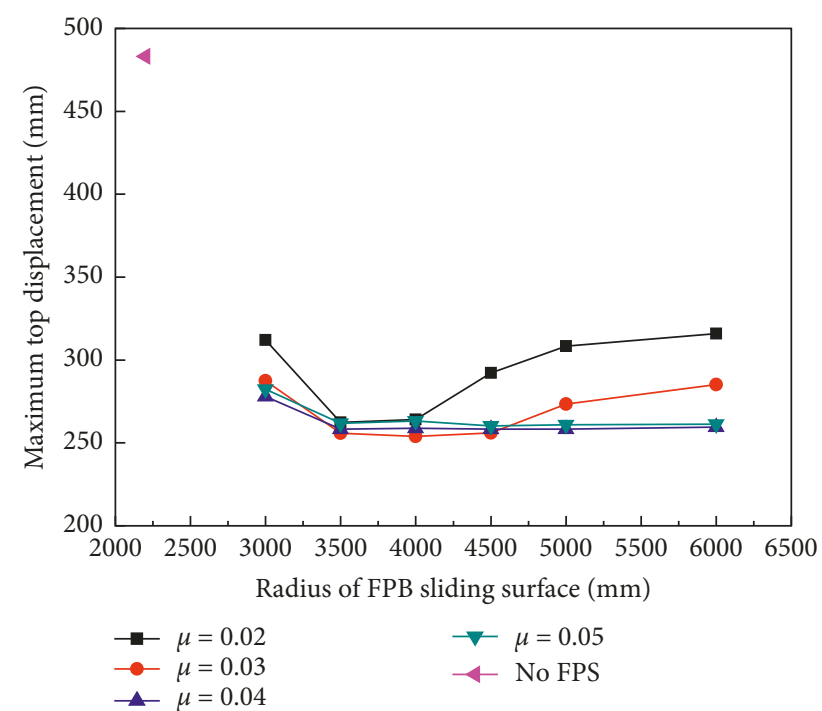

Figure 22: The maximum top displacement of T4S tower with $R_{\mathrm{d}}$ and $\mu$ in the Y direction under L0689S wave.

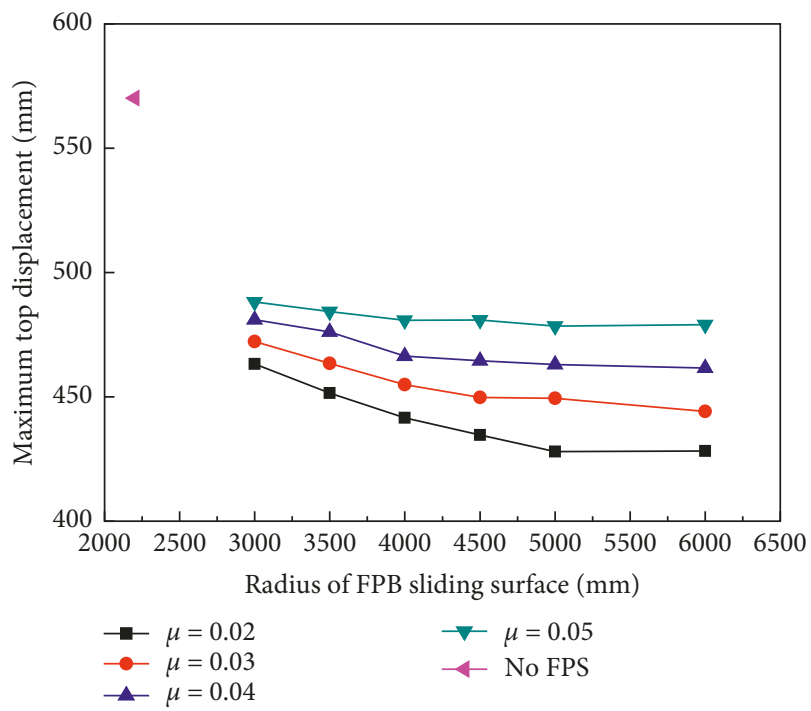

Figure 23: The maximum drift of T4 tower with $R_{\mathrm{d}}$ and $\mu$ in the $\mathrm{X}$ direction under L0223S wave.

are presented as well. The interstory drift-story height curves have the similar shape between the controlled structure and the uncontrolled structure. The interstory drift regresses near the height where the stiffened stories are set. Either the structure is set FPS or not, the interstory drifts are all smaller than the limited value of $1 / 100$ stipulated by the codes.

The comparison of the maximum absolute acceleration on the top of the towers with and without FPS is shown in Table 5. After the FPS and damper are set, the reduction rate of the acceleration on the top of the towers is from $5.79 \%$ to $20.88 \%$ in the $\mathrm{X}$ direction and from $0.28 \%$ to $14.25 \%$ in the $\mathrm{Y}$ direction under different earthquake wave actions.

Figures 39 and 40 show the damage pattern of the structure under L0689S wave when FPS and viscous damper are not set or are set, respectively. Before the FPS and the viscous damper were set, most of the coupling beams

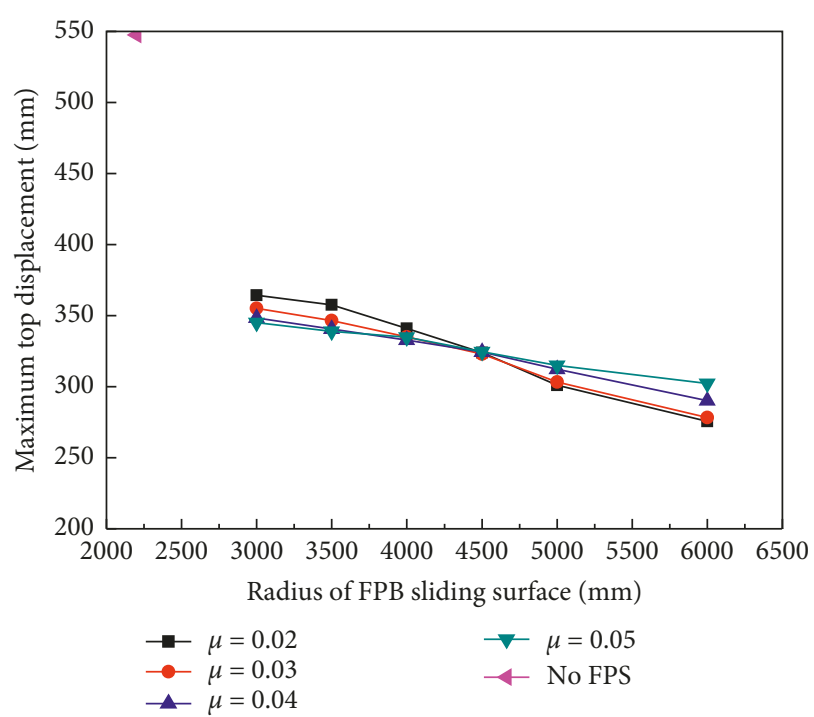

Figure 24: The maximum drift of T4S tower with $R_{\mathrm{d}}$ and $\mu$ in the Y direction under L0223S wave.

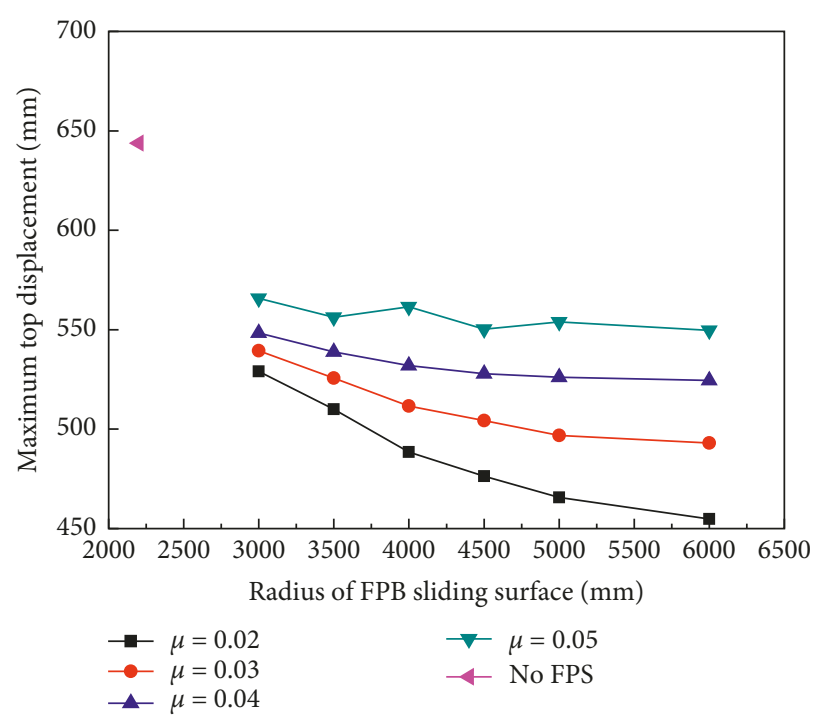

FIgURE 25: The maximum top displacement of T4S tower with $R_{\mathrm{d}}$ and $\mu$ in the $\mathrm{X}$ direction under L6501S wave.

reached yielding points and the damage of the coupling beams in T3S tower and T4S tower are more serious than those of the other two towers. Many frame beams and some columns reached yielding points. A small amount of reinforcement in walls was yielded. However, only few of the coupling beams reached the ultimate state, and all the other members of the structure did not reach the ultimate state. No yielding occurred in the members of sky corridor bridge, which are still in elastic states. The number of yielding frame beams decreased after the FPS and the viscous dampers were set. Moreover, the damage extent of the frame beams, columns, and walls also reduced.

The base shear forces of the sky corridor bridge acting on the top of T4S tower in the X and Y direction under L0689S wave are shown in Figures 41 and 42 . When no FPS was set 


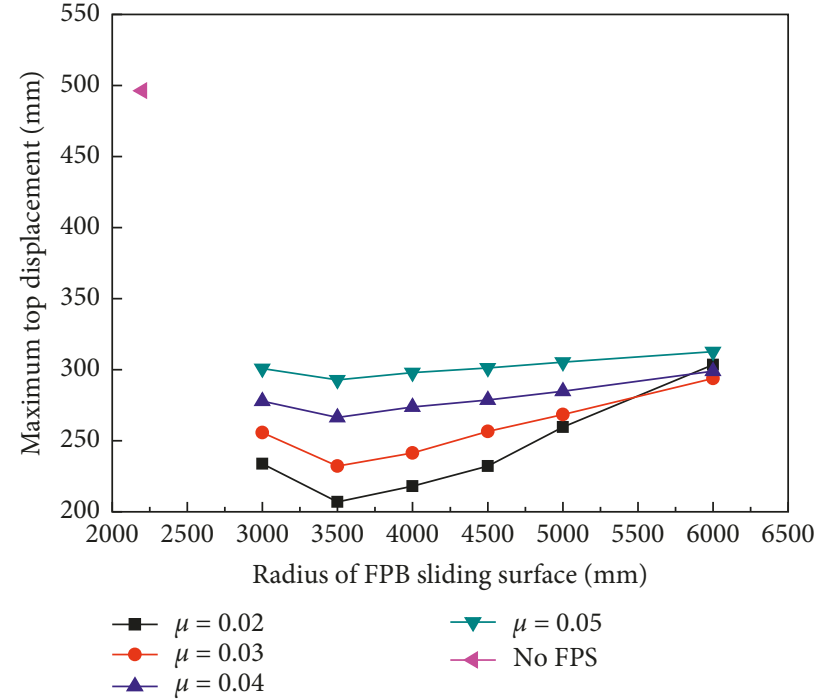

Figure 26: The maximum top displacement of T4S tower with $R_{\mathrm{d}}$ and $\mu$ in the Y direction under L6501S wave.

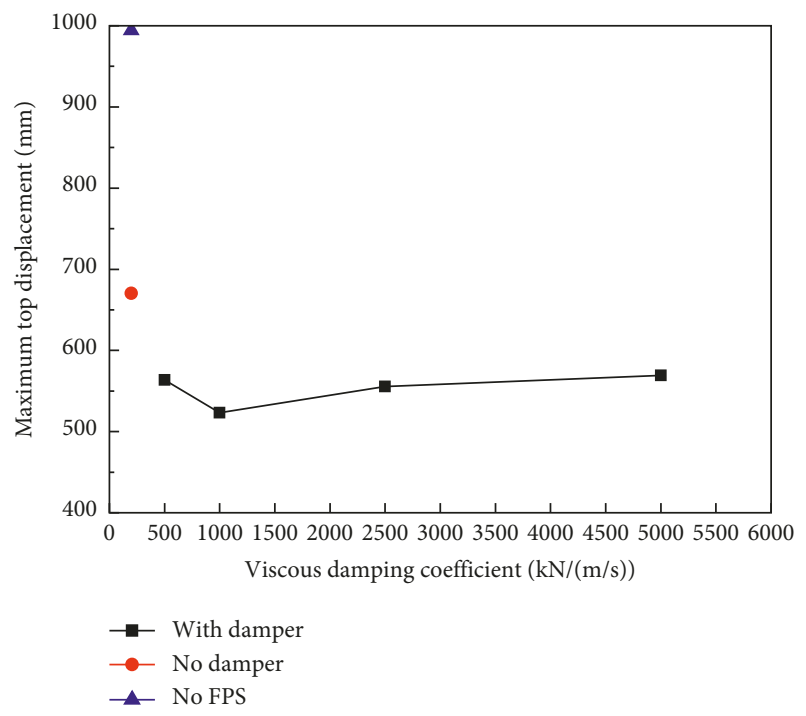

FIGURE 27: The maximum top displacement of T2 tower with FPBs $\left(R_{\mathrm{d}}=4500, \mu=0.02\right)$ and varying viscous damping coefficients in the $\mathrm{X}$ direction under L0689S wave.

between the sky corridor bridge and the towers, the base shear forces caused by local vibration accounted for a larger value at the front of time history. After the FPS or the FPS with damper was set, the base shear forces remarkably decreased. This indicates that if the restraint of towers to the bridge is weakened, the seismic action transferred by towers to bridge also reduces. Meanwhile, when the viscous dampers were used to attach on FPS, it changed almost nothing about the time history of the base shear forces.

The time history of the energy distribution in the structure with or without FPS and viscous damper under L0689S wave are shown in Figures 43 and 44, respectively. Before the FPS and the viscous damper were set, the rate of the nonlinear energy dissipation occupied about $23 \%$, which was mainly dissipated by the beam, column, and wall. After

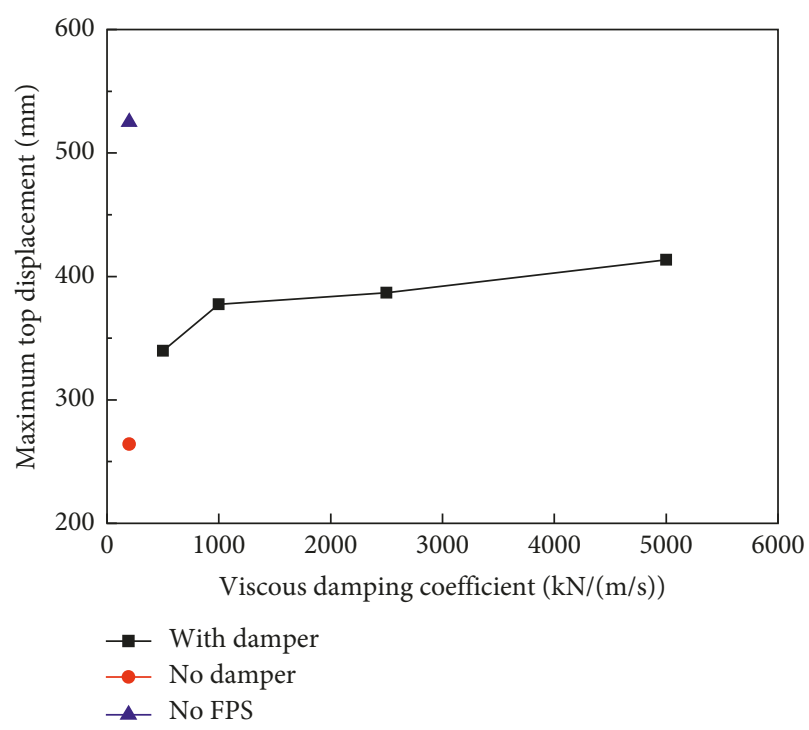

FIgURE 28: The maximum top displacement of T2 tower with FPBs $\left(R_{\mathrm{d}}=4500, \mu=0.02\right)$ and varying viscous damping coefficients in the $\mathrm{Y}$ direction under L0689S wave.

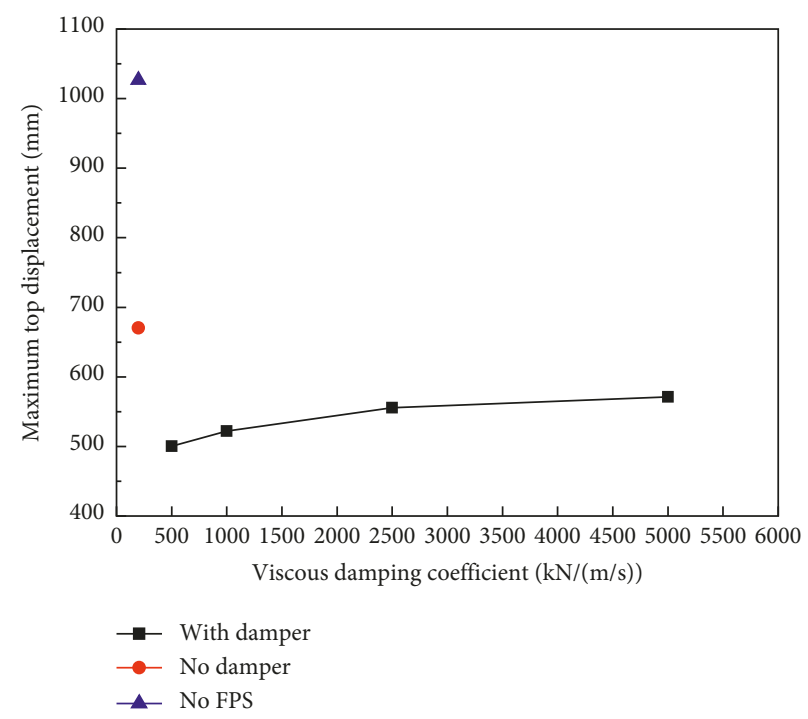

Figure 29: The maximum top displacement of T4S tower with FPBs $\left(R_{\mathrm{d}}=4500, \mu=0.02\right)$ and varying viscous damping coefficients in the $\mathrm{X}$ direction under L0689S wave.

the FPS and the viscous damper were set, the rate of the nonlinear energy dissipation increased to about 36\%. However, the total input seismic energy decreased. Under the action of L0889S wave, when the FPS and the viscous were not set, the total input seismic energy of the structure was $5.063 \times 10^{5} \mathrm{kN}-\mathrm{m}$, and when the FPS and the viscous were set, it was $4.738 \times 10^{5} \mathrm{kN}-\mathrm{m}$. Furthermore, the FPS energy dissipation occupied the $35 \%$ of the total nonlinear energy dissipation (Figure 45). Correspondingly, the energy dissipated by the beam, column, and wall was cut down. As a result, the damage of structural members was reduced.

The amount of the energy dissipation by the viscous damper was relatively small (Figure 44). Here, the main function of the viscous damper is to reduce the horizontal 


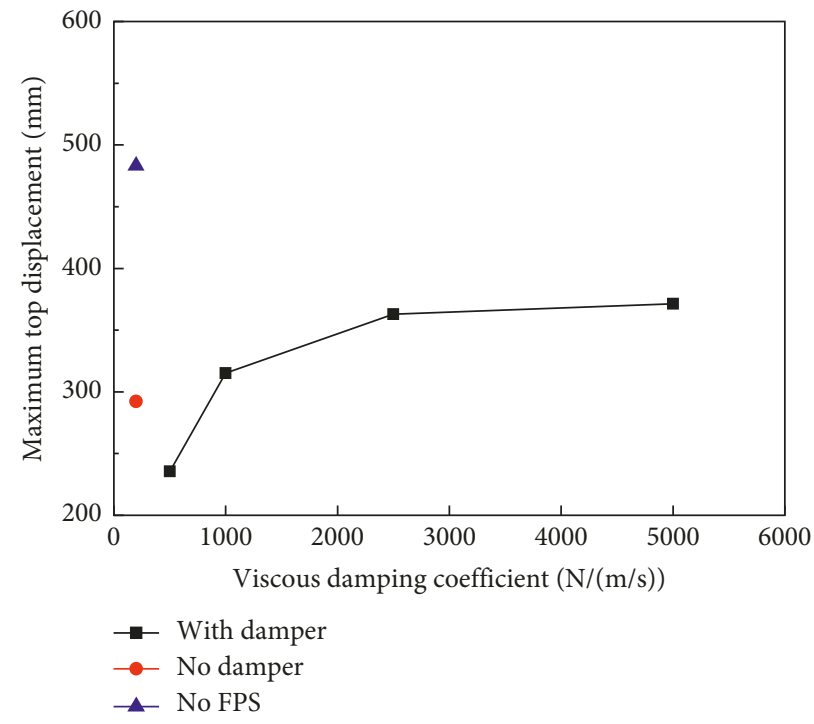

Figure 30: The maximum top displacement of T4S tower with FPBs $\left(R_{\mathrm{d}}=4500, \mu=0.02\right)$ and varying viscous damping coefficients in the $\mathrm{Y}$ direction under L0689S wave.

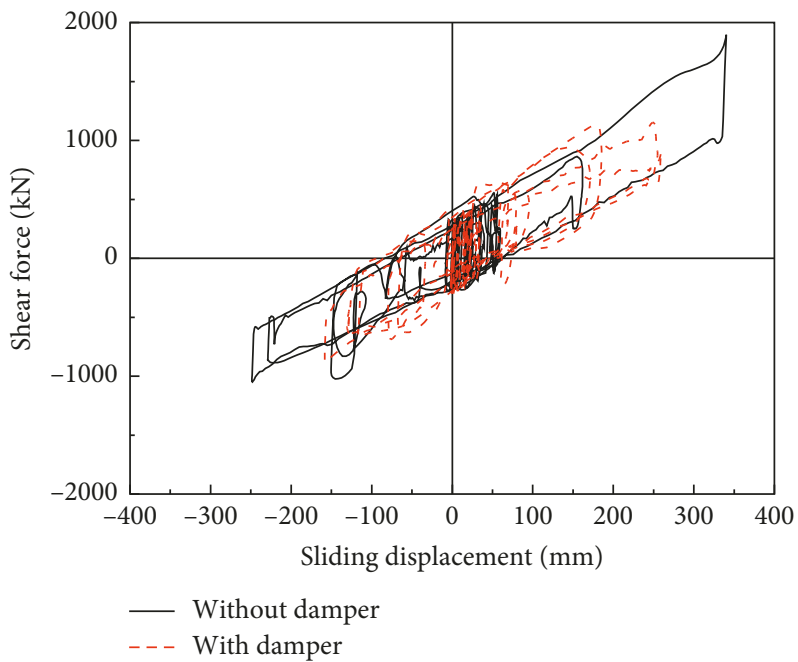

FIgURE 31: The trace of the shear force to sliding displacement of FPB15 (Figure 5) in the X direction under L0689S wave.

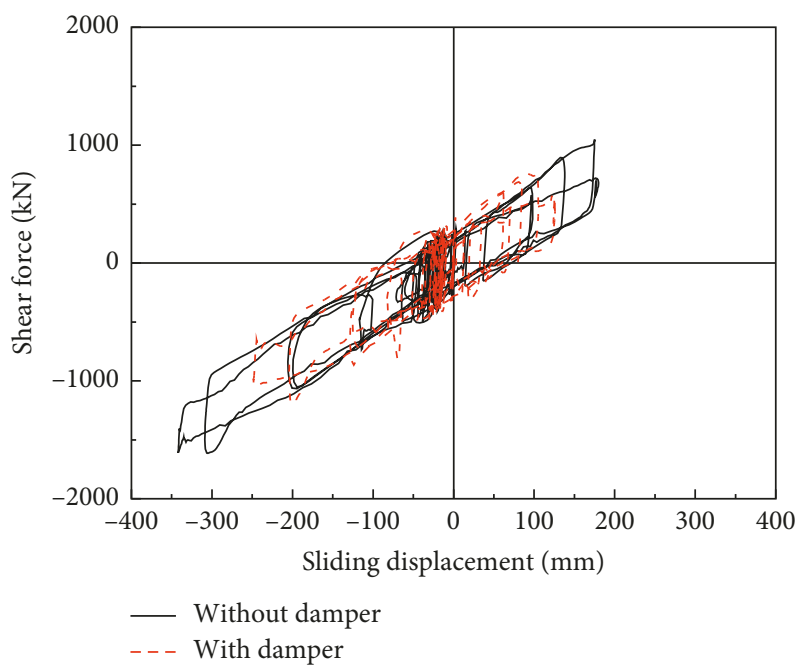

FIgURE 32: The trace of the shear force to sliding displacement of FPB15 (Figure 5) in the Y direction under L0689S wave. 


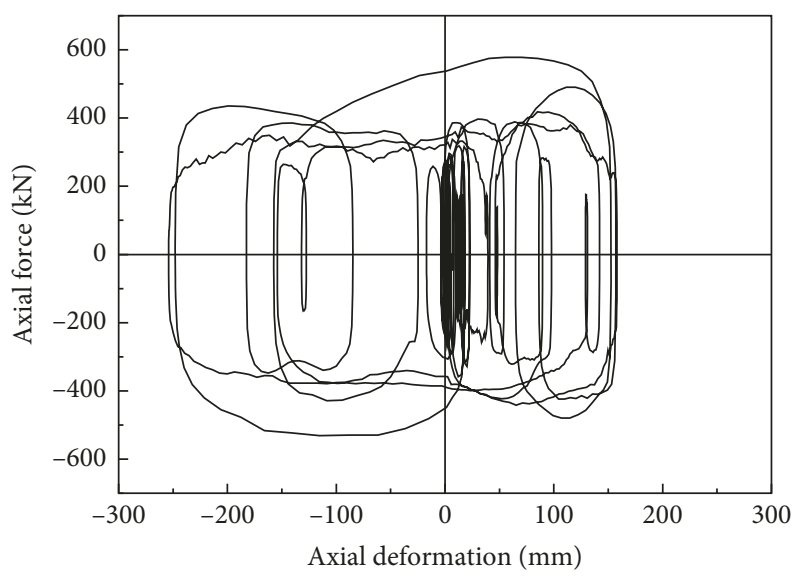

Figure 33: The trace of the axial force to axial deformation of damper D9 under L0689S wave.

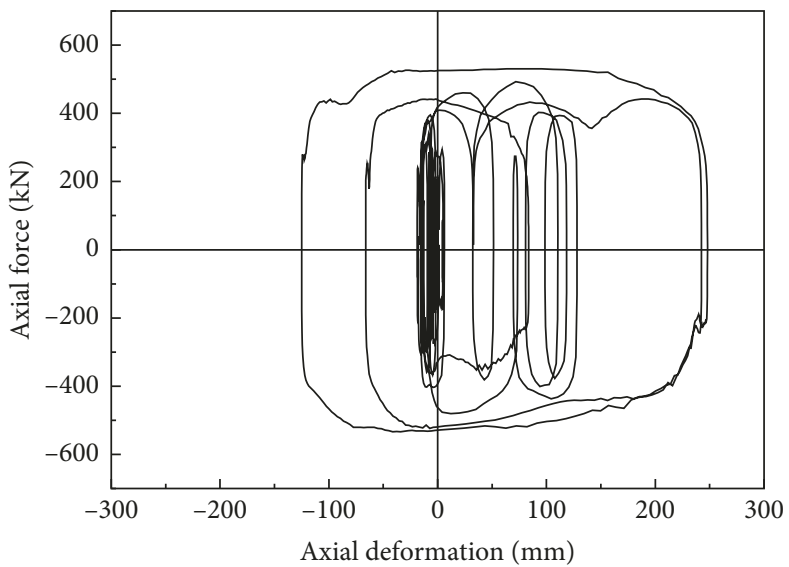

Figure 34: The trace of the axial force to axial deformation of damper D10 under L0689S wave.

TABLE 4: Maximum interstory drift of the structure.

\begin{tabular}{|c|c|c|c|c|c|c|c|}
\hline \multirow[b]{2}{*}{ Wave } & \multirow[b]{2}{*}{ Tower } & \multicolumn{3}{|c|}{$\mathrm{X}$ direction (rad) } & \multicolumn{3}{|c|}{ Y direction (rad) } \\
\hline & & $\begin{array}{l}\text { No FPS and no } \\
\text { damper }\end{array}$ & $\begin{array}{c}\text { With FPS and } \\
\text { damper }\end{array}$ & $\begin{array}{c}\text { Reduction rate } \\
(\%)\end{array}$ & $\begin{array}{c}\text { No FPS and no } \\
\text { damper }\end{array}$ & $\begin{array}{c}\text { With FPS and } \\
\text { damper }\end{array}$ & $\begin{array}{c}\text { Reduction rate } \\
(\%)\end{array}$ \\
\hline \multirow{4}{*}{ L0689S } & $\mathrm{T} 2$ & $1 / 183$ & $1 / 257$ & 28.79 & $1 / 252$ & $1 / 331$ & 23.87 \\
\hline & T3S & $1 / 176$ & $1 / 246$ & 28.46 & $1 / 223$ & $1 / 318$ & 29.87 \\
\hline & $\mathrm{T} 4 \mathrm{~S}$ & $1 / 167$ & $1 / 230$ & 27.39 & $1 / 232$ & $1 / 333$ & 30.33 \\
\hline & T5 & $1 / 192$ & $1 / 251$ & 23.51 & $1 / 287$ & $1 / 379$ & 24.27 \\
\hline \multirow{4}{*}{ L0223S } & $\mathrm{T} 2$ & $1 / 325$ & $1 / 385$ & 14.92 & $1 / 342$ & $1 / 423$ & 19.15 \\
\hline & T3S & $1 / 317$ & $1 / 367$ & 13.62 & $1 / 328$ & $1 / 395$ & 16.96 \\
\hline & $\mathrm{T} 4 \mathrm{~S}$ & $1 / 303$ & $1 / 352$ & 13.92 & $1 / 349$ & $1 / 419$ & 16.71 \\
\hline & $\mathrm{T} 5$ & $1 / 299$ & $1 / 388$ & 22.94 & $1 / 354$ & $1 / 413$ & 14.29 \\
\hline \multirow{4}{*}{ L6501S } & $\mathrm{T} 2$ & $1 / 275$ & $1 / 335$ & 17.91 & $1 / 345$ & $1 / 424$ & 18.63 \\
\hline & T3S & $1 / 270$ & $1 / 337$ & 19.88 & $1 / 367$ & $1 / 443$ & 17.16 \\
\hline & T4S & $1 / 281$ & $1 / 324$ & 13.27 & $1 / 344$ & $1 / 401$ & 14.21 \\
\hline & T5 & $1 / 261$ & $1 / 319$ & 18.18 & $1 / 357$ & $1 / 429$ & 16.78 \\
\hline
\end{tabular}

slip of the friction pendulum and limit the slip within the design value.

\section{Conclusions}

In order to reduce the earthquake responses and the member forces of a connected multitower structure, a passive control strategy with a friction pendulum tuned mass damper (FPTMD) was employed. Based on the analytical results, conclusions can be drawn as follows:

(1) The friction pendulum tuned mass damper (FPTMD) composed of friction pendulum bearing, viscous damper, and sky corridor bridge can effectively reduce the seismic response of the structure, 


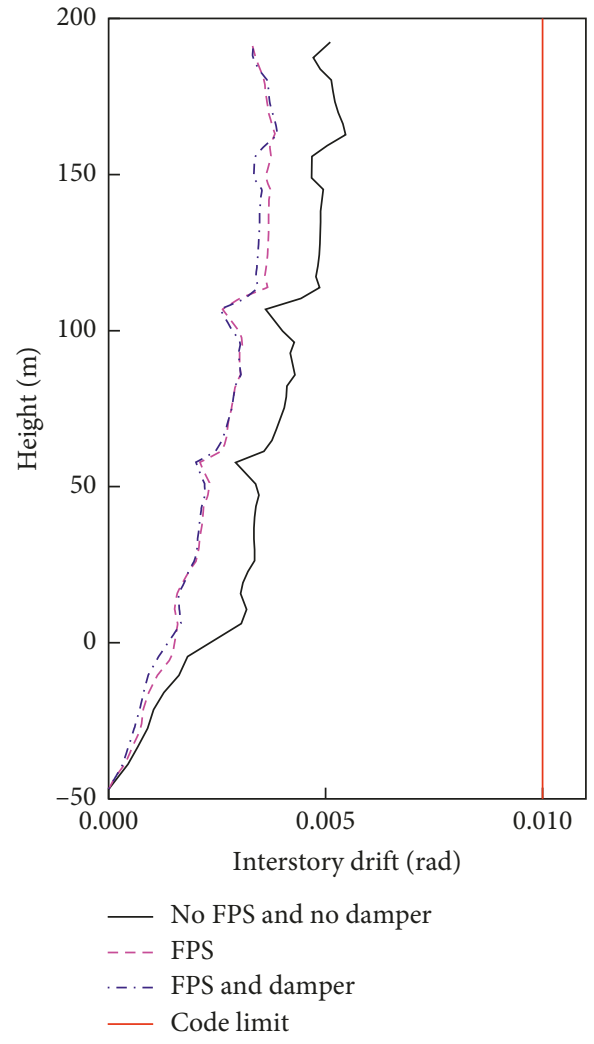

FIgURE 35: Interstory drift of $\mathrm{T} 2$ tower in the $\mathrm{X}$ direction under L0689S wave.

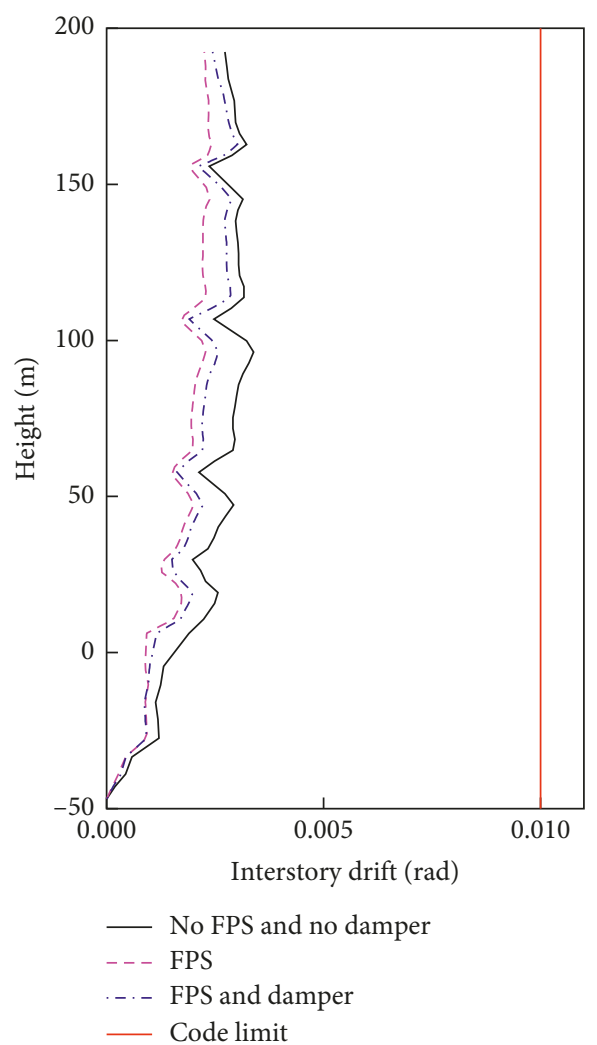

Figure 36: Interstory drift of $\mathrm{T} 2$ tower in the $\mathrm{Y}$ direction under L0689S wave.

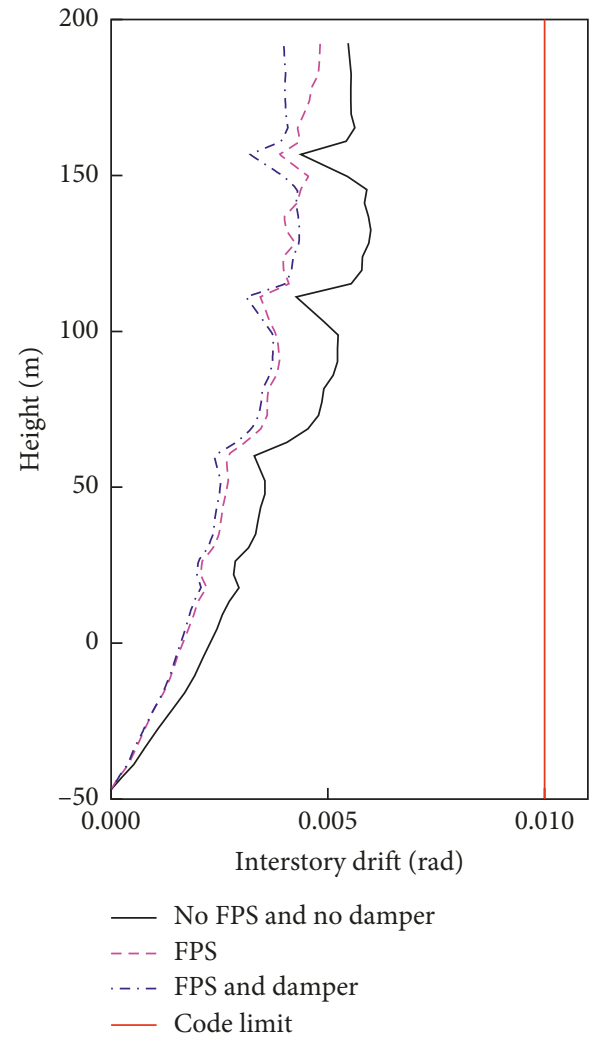

FIgURE 37: Interstory drift of T4S tower in the $\mathrm{X}$ direction under L0689S wave.

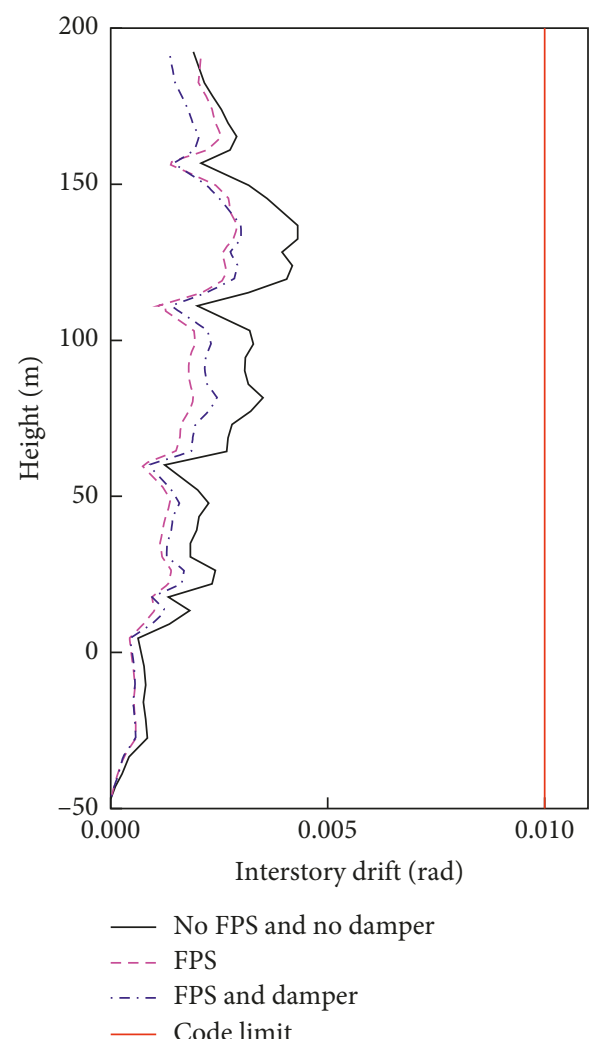

FIGURE 38: Interstory drift of T4S tower in the Y direction under L0689S wave. 
TABle 5: Maximum absolute acceleration on the top of the towers.

\begin{tabular}{|c|c|c|c|c|c|c|c|}
\hline \multirow[b]{2}{*}{ Wave } & \multirow[b]{2}{*}{ Tower } & \multicolumn{3}{|c|}{$\mathrm{X}$ direction $\left(\mathrm{mm} / \mathrm{s}^{2}\right)$} & \multicolumn{3}{|c|}{$\mathrm{Y}$ direction $\left(\mathrm{mm} / \mathrm{s}^{2}\right)$} \\
\hline & & $\begin{array}{l}\text { No FPS and no } \\
\text { damper }\end{array}$ & $\begin{array}{c}\text { With FPS and } \\
\text { damper }\end{array}$ & $\begin{array}{c}\text { Reduction rate } \\
(\%)\end{array}$ & $\begin{array}{l}\text { No FPS and no } \\
\text { damper }\end{array}$ & $\begin{array}{l}\text { With FPS and } \\
\text { damper }\end{array}$ & $\begin{array}{l}\text { Reduction rate } \\
(\%)\end{array}$ \\
\hline \multirow{4}{*}{ L0689S } & $\mathrm{T} 2$ & 3366.8 & 2759.5 & 18.04 & 2557.8 & 2359.3 & 7.76 \\
\hline & T3S & 3251.2 & 2572.2 & 20.88 & 2512.6 & 2306.8 & 8.19 \\
\hline & $\mathrm{T} 4 \mathrm{~S}$ & 3184.8 & 2551.7 & 19.88 & 2224.6 & 2218.3 & 0.28 \\
\hline & T5 & 3007.1 & 2624.7 & 12.72 & 2167.5 & 2120.1 & 2.19 \\
\hline \multirow{4}{*}{ L0223S } & $\mathrm{T} 2$ & 3428.7 & 2993.7 & 12.69 & 2200.0 & 2024.9 & 7.96 \\
\hline & T3S & 3147.7 & 2965.3 & 5.79 & 2451.7 & 2102.3 & 14.25 \\
\hline & T4S & 3272.3 & 2805.5 & 14.27 & 2314.1 & 2160.0 & 6.66 \\
\hline & $\mathrm{T} 5$ & 3397.3 & 2840.7 & 16.38 & 2437.4 & 2275.8 & 6.63 \\
\hline \multirow{4}{*}{ L6501S } & $\mathrm{T} 2$ & 2955.6 & 2682.3 & 9.25 & 2125.4 & 2050.3 & 3.53 \\
\hline & T3S & 2844.2 & 2664.7 & 6.31 & 2308.9 & 2125.5 & 7.94 \\
\hline & $\mathrm{T} 4 \mathrm{~S}$ & 2862.9 & 2649.2 & 7.46 & 2296.7 & 2130.5 & 7.24 \\
\hline & T5 & 3067.5 & 2737.4 & 10.76 & 2339.1 & 2194.2 & 6.19 \\
\hline
\end{tabular}

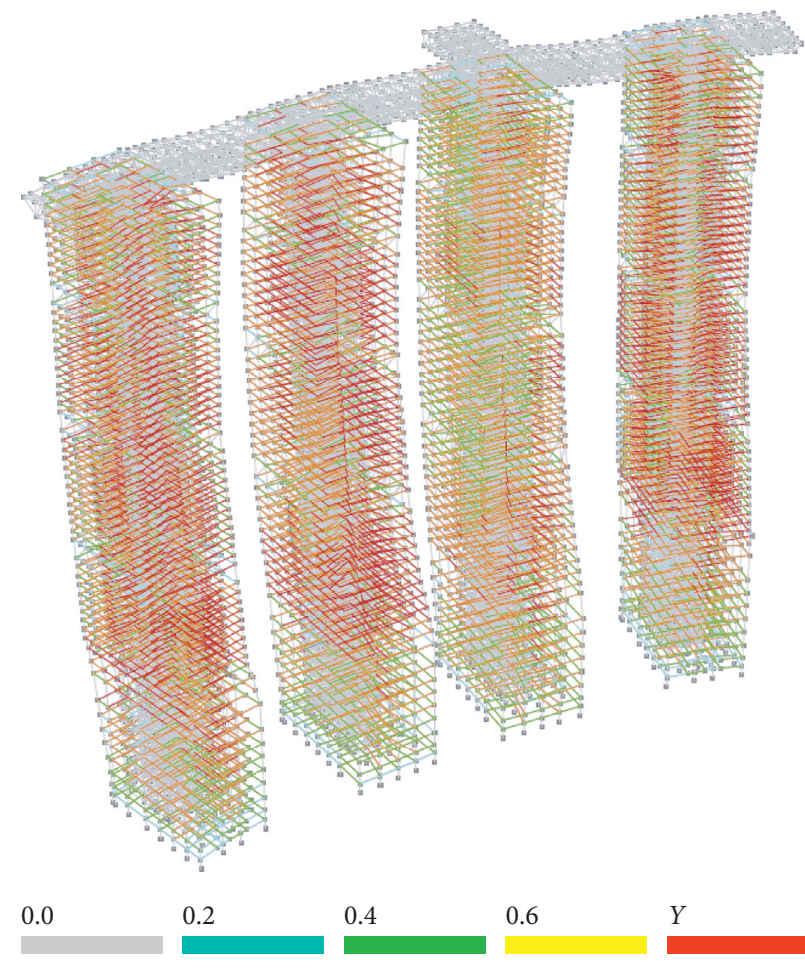

(a)

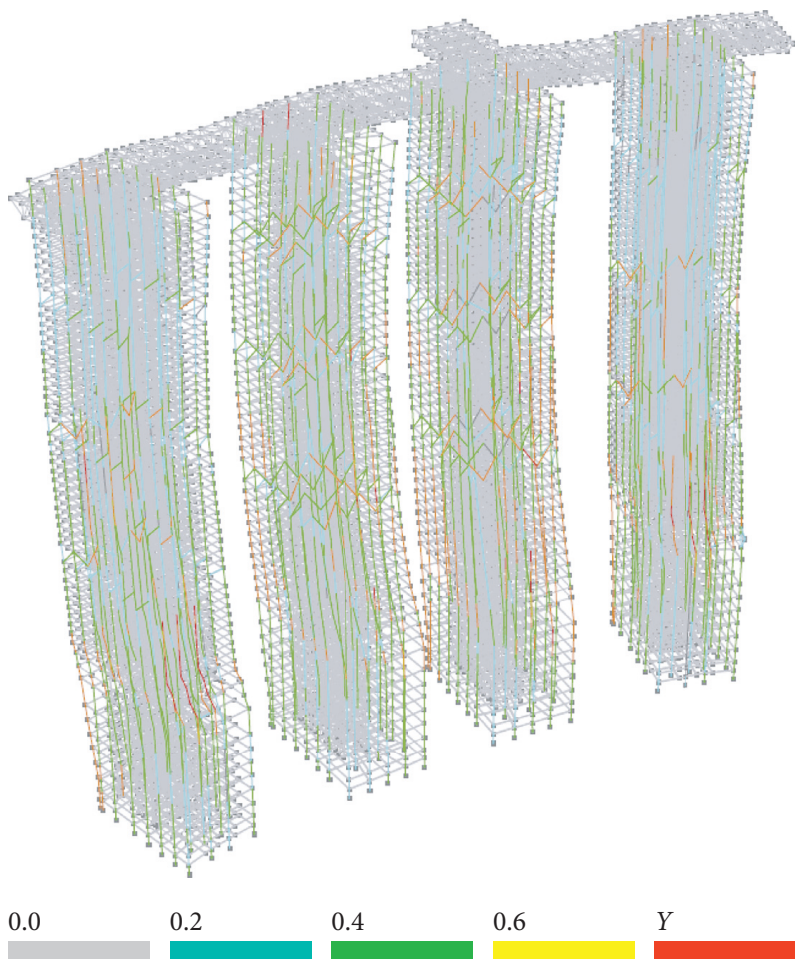

(b)

FIgUre 39: Damage patterns under L0689S wave (no PFS and no damper). (a) Beam yielding. (b) Column yielding.

including deformation of the structure and damage extent of the structure members.

(2) In theory, when the frequency of a tuned mass damper (TMD) is tuned to be close to the fundamental frequency of the primary structure, the effect of seismic reduction will be the best. However, there are many factors that affect the effect of seismic reduction, such as more vibration modes of the primary structure participating in earthquake response, damping leads the FPTMD frequency change, and the damage of structure causes the change of the dynamic property of the primary structure. Therefore, it is unsuitable to simply set the frequency of FPTMD to the frequency of the first mode of the tower. The determination of FPS parameters needs to be searched by a series of calculations to reach the better effect of seismic reduction 2 .

(3) When the sky corridor bridge and towers are rigidly connected, the relative displacement among the towers caused by the earthquake will lead to larger interaction force between sky corridor 


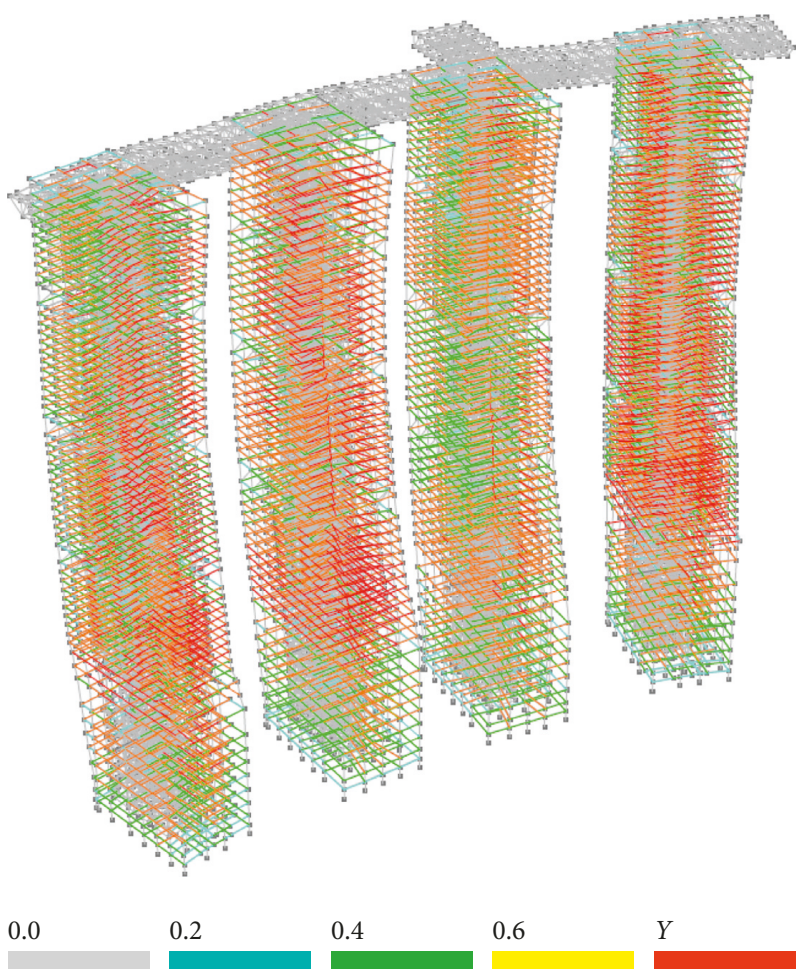

(a)

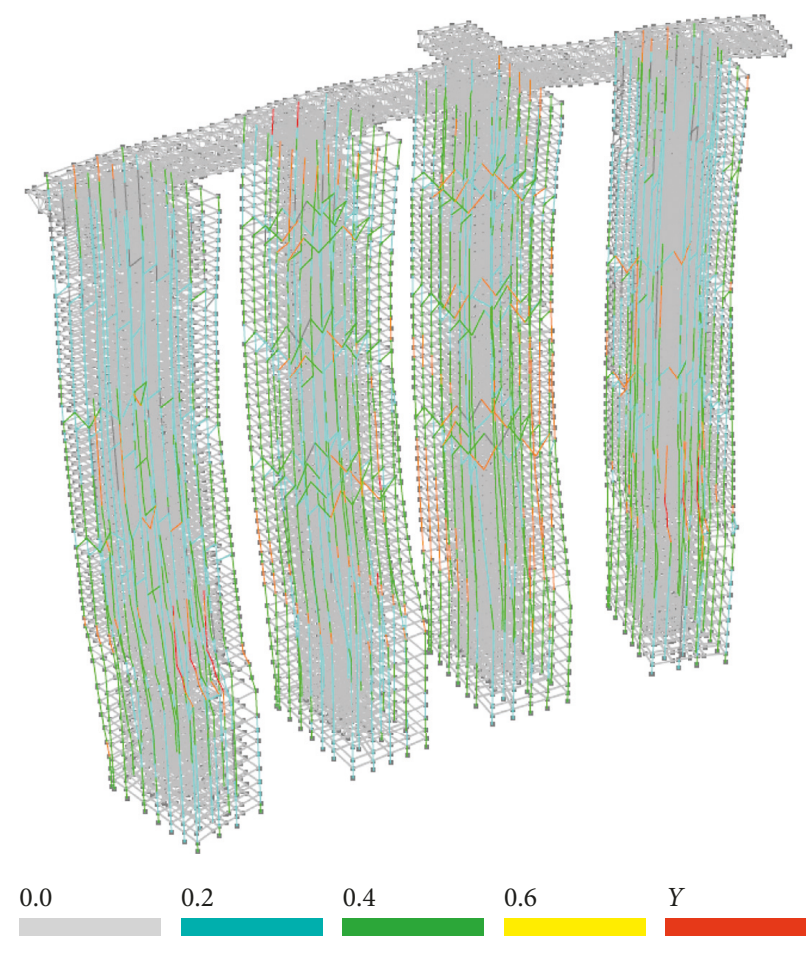

(b)

FIgURE 40: Damage patterns under L0689S wave (FPS and damper). (a) Beam yielding. (b) Column yielding.

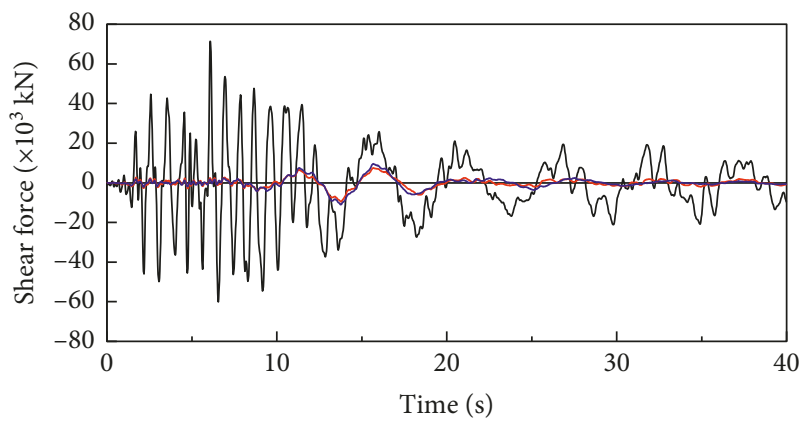

— No FPS and no damper
— FPS
— FPS and damper

FIGURE 41: The base shear of the sky corridor bridge acting on the top of T4S tower in the X direction under L0689S wave.

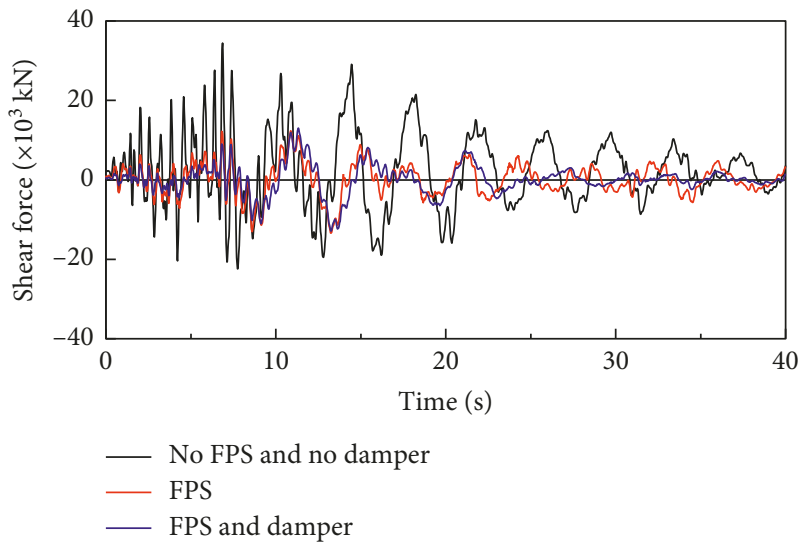

FIGURE 42: The base shear of the sky corridor bridge acting on the top of T4S tower in the Y direction under L0689S wave. 


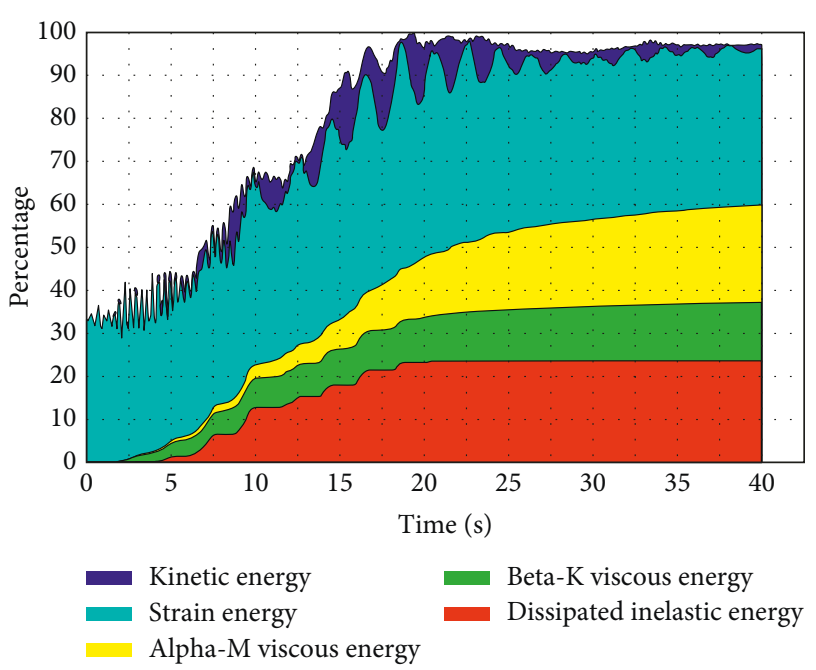

FIgURE 43: The time history of the energy distribution in the structure under L0689S wave (no FPS and no damper).

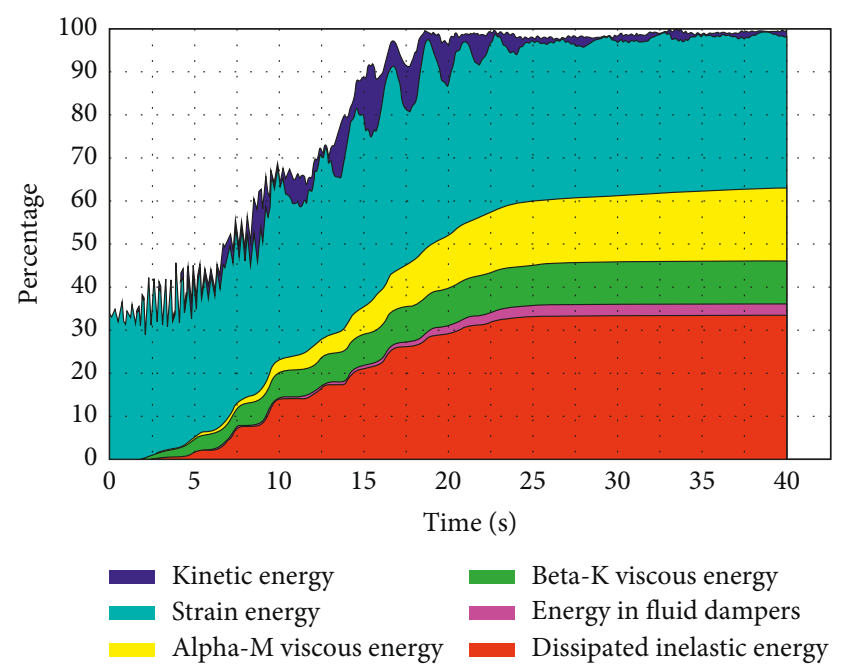

FIGURE 44: The time history of the energy distribution in the structure under L0689S wave (FPS and damper).

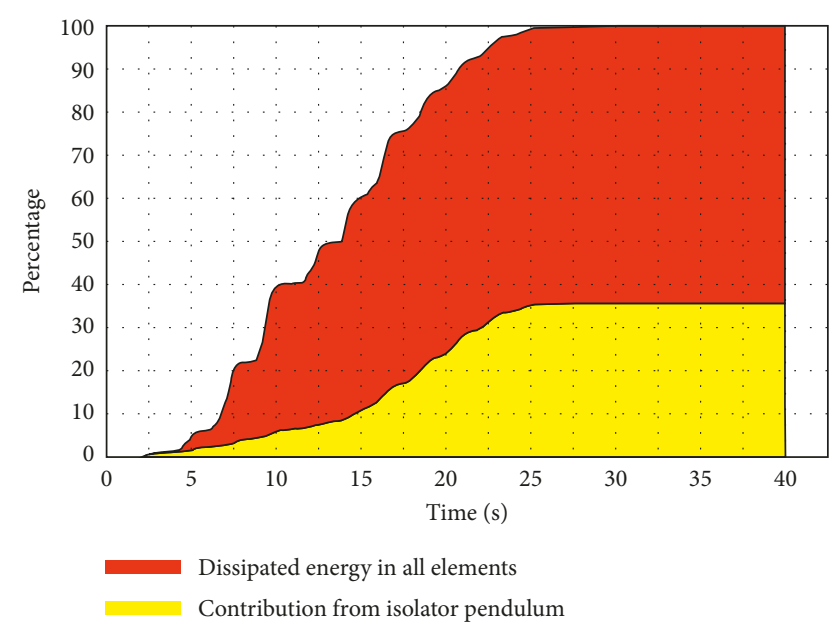

FIgURE 45: The rate of the FPS energy dissipation in the total nonlinear energy dissipation under L0689S wave (FPS and damper). bridge and towers. The isolation device set between the bridge and the towers can reduce the interaction remarkably, and the members of the sky corridor bridge can keep in elastic state even under the action of large earthquake.

(4) Compared with the friction pendulum, the viscous damper has less energy dissipation. However, the viscous damper can reduce the horizontal slip displacement of the friction pendulum and limit the slip displacement within the design value.

(5) Neither columns nor walls reached the ultimate state. The structure meets the requirement in Chinese Design Codes of "no collapse under rare earthquake." In addition to that, the deformation of the structure stays inside the limitation stipulated in Chinese Design Codes as well.

\section{Data Availability}

The written data used to support the findings of this study are included within the article. The digital data used to support the findings of this study are available from the corresponding author upon request.

\section{Conflicts of Interest}

The authors declare that there are no conflicts of interest regarding the publication of this paper.

\section{Acknowledgments}

The authors are grateful for the financial support received from Scientific Research Program of Shanghai Science and Technology Committee (Grant no. 17DZ1203200).

\section{References}

[1] X. L. Lu, L. Z. Chen, Y. Zhou, and Z. H. Huang, "Shaking table model tests on a complex high-rise building with two towers of different height connected by trusses," Structural Design of Tall and Special Buildings, vol. 18, no. 7, pp. 765-788, 2009.

[2] Y. Zhou, X. L. Lu, W. S. Lu, and Z. J. He, "Shake table testing of a multi-tower connected hybrid structure," Earthquake Engineering and Engineering Vibration, vol. 8, no. 1, pp. 47-59, 2009.

[3] X. H. Wu, Y. F. Sun, M. Z. Rui, Y. Man, L. S. Li, and D. Z. Liu, "Elasto-plastic time history analysis of an asymmetrical twintower rigid-connected structure," Computers and Concrete, vol. 12, no. 2, pp. 211-228, 2013.

[4] D. Y. Zhou, C. T. Guo, X. H. Wu, and B. Zhang, "Seismic evaluation of a multi-tower connected building by using three software programs with experimental verification," Shock and Vibration, vol. 2016, Article ID 8215696, 18 pages, 2016.

[5] A. V. Bhaskararao and R. S. Jangid, "Seismic analysis of structures connected with friction dampers," Engineering Structures, vol. 28, no. 5, pp. 690-703, 2006.

[6] R. Hwasung, P. C. Gian, and L. Diego, "Seismic response of adjacent steel structures connected by passive device," Advances in Structural Engineering, vol. 14, no. 3, pp. 499-517, 2011. 
[7] X. W. Chen and X. L. Han, "Research summary of long-span connected tall building structure with viscous dampers," Structural Design of Tall and Special Buildings, vol. 19, no. 4, pp. 439-456, 2010.

[8] P. Huber, "Seismic damping systems with TMDs for high rise buildings," in Proceedings of 16th World Conference on Earthquake Engineering, Santiago, Chile, January 2017.

[9] B. Garrido and M. Sarrazin, "Effectiveness of tuned sass dampers (TMD) for earthquake protection in Chilean buildings," in Proceedings of 16th World Conference on Earthquake Engineering, Santiago, Chile, January 2017.

[10] L. L. Chung, L. Y. Wu, K. H. Lien, H. H. Chen, and H. H. Huang, "Optimal design of friction pendulum tuned mass damper with varying friction coefficient," Structural Control and Health Monitoring, vol. 20, no. 4, pp. 544-559, 2013.

[11] G. Mosqueda, A. S. Whittaker, and G. L. Fenves, "Characterization and modeling of friction pendulum bearings subjected to multiple components of excitation," Journal of Structural Engineering, vol. 130, no. 3, pp. 433-442, 2004.

[12] T. C. Becker, Y. Bao, and S. A. Mahin, "Extreme behavior in a triple friction pendulum isolated frame," Earthquake Engineering \& Structural Dynamics, vol. 46, no. 15, pp. 26832698, 2017.

[13] X. H. Wu, F. T. Sun, X. L. Lu, and J. Qian, "Nonlinear time history analysis of China Pavilion for expo2010 Shanghai China," Structural Design of Tall and Special Buildings, vol. 23, no. 10, pp. 721-739, 2014

[14] H. S. Lee, D. H. Jeong, and K. R. Hwang, "Analytical simulation of reversed cyclic lateral behaviors of an RC shear wall sub-assemblage," Computers and Concrete, vol. 10, no. 2, pp. 173-196, 2012.

[15] X. H. Wu, Y. M. Li, and Y. L. Zhang, "Elasto-plastic time history analysis of a 117-story high structure," Computers and Concrete, vol. 19, no. 1, pp. 7-17, 2017.

[16] X. W. Chen, X. L. Han, F. N. Luo, and S. G. Wu, "Fiber element based elastic-plastic analysis procedure and engineering application," in Proceedings of Twelfth East AsiaPacific Conference on Structural Engineering and Construction, pp. 1807-1815, Hong Kong, January 2011.

[17] Ministry of Housing and Urban-Rural Development of the People's Republic of China, Code for Seismic Design of Buildings (GB50011-2010), China Architecture and Building Press, Beijing, China, 2010.

[18] Ministry of Construction of the People's Republic of China, Technical Specification for Concrete Structures of Tall Building (JGJ3-2010), China Architecture and Building Press, Beijing, China, 2010.

[19] Computer \& Structures Inc., Components and Elements for Perform-3D and Perform-Collapse, Berkeley, CA, USA, 2011.

[20] X. H. Wu and B. Zhang, "The transformation of nonlinear structure analysis model from NosaCAD to ABAQUS and Perform-3D," in Proceedings of 15th World Conference on Earthquake Engineering, Lisbon, Portugal, September 2012. 


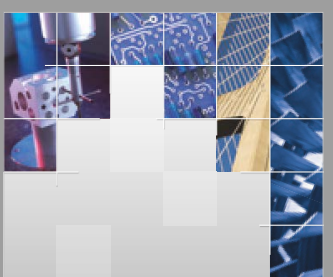

\section{Enfincering}
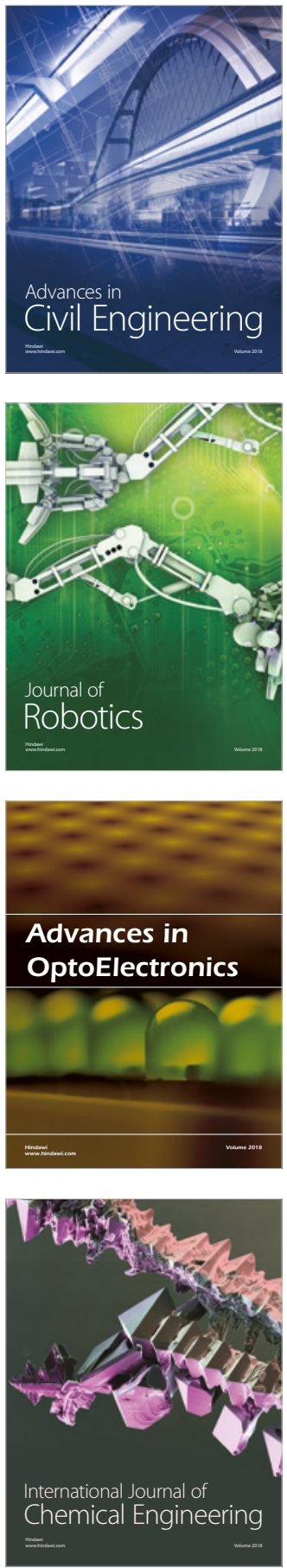

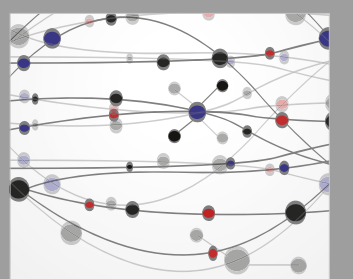

\section{Rotating \\ Machinery}

The Scientific World Journal

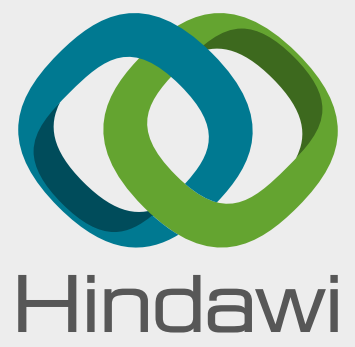

Submit your manuscripts at

www.hindawi.com
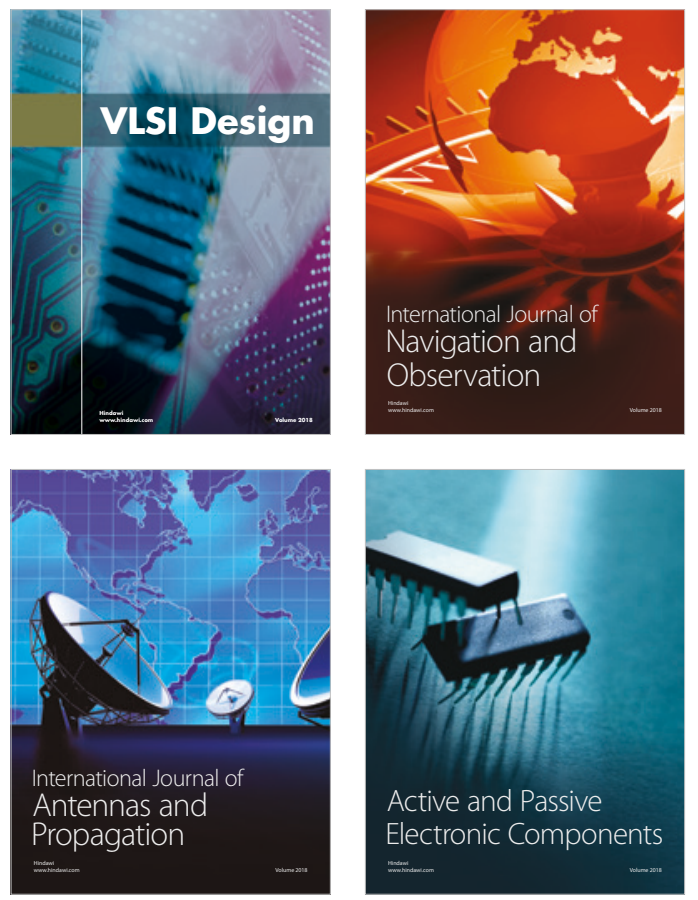
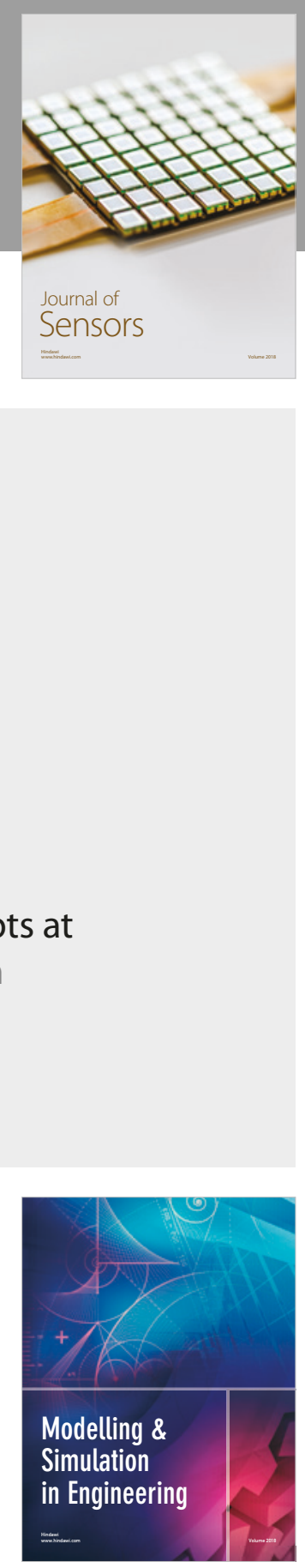

\section{Advances \\ Multimedia}
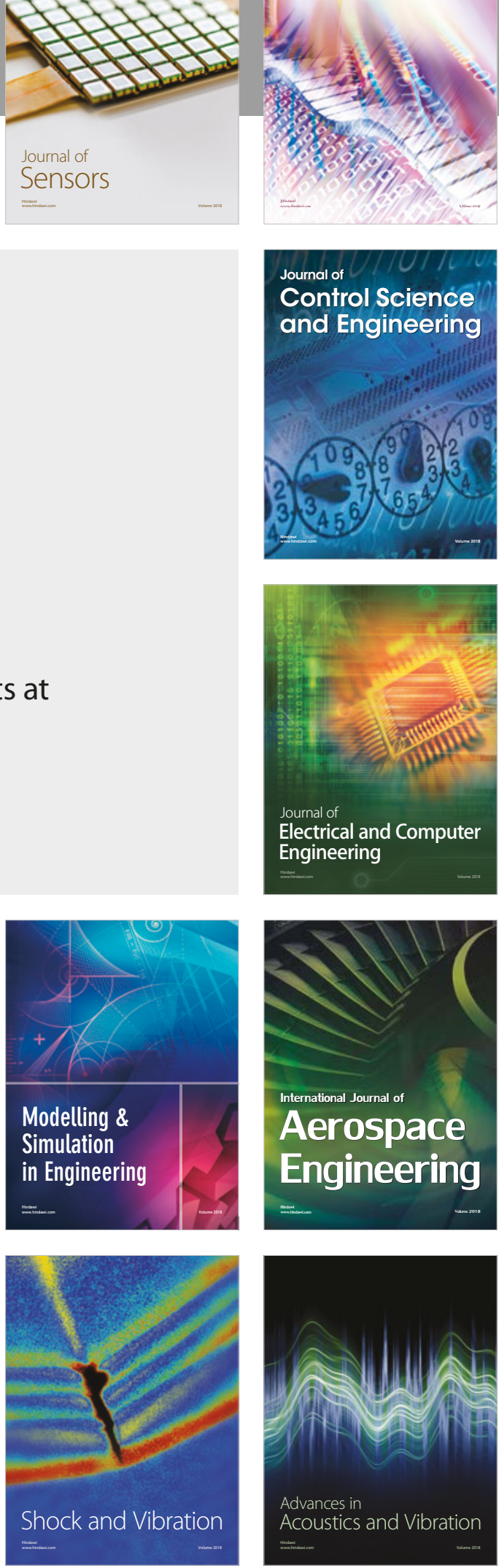